\title{
Patentes sobre fotografía en España (1839-1939). Análisis documental: contenidos y solicitantes
}

\author{
Juan Miguel Sánchez-Vigil*, María Olivera-Zaldua*, Juan Carlos Marcos-Recio** \\ * Facultad de Ciencias de la Documentación, Universidad Complutense de Madrid \\ Correo-e: jmvigil@ucm.es | ORCID iD: https://orcid.org//0000-0002-1640-9295 \\ Correo-e: molivera@ucm.es | ORCID iD: https://orcid.org/0000-0001-6335-9094 \\ ** Facultad de Ciencias de la Información, Universidad Complutense de Madrid \\ Correo-e: jmarcos@ucm.es | ORCID iD: https://orcid.org/0000-0003-0890-1092
}

Recibido: 22-09-2017; 2a versión: 10-11-2017; Aceptado: 10-11-2017

Cómo citar este artículo/Citation: Sánchez-Vigil, J. M.; Olivera-Zaldua, M.; Marcos-Recio, J. C. (2018). Patentes sobre fotografía en España (1839-1939). Análisis documental: contenidos y solicitantes. Revista Española de Documentación Científica, 41 (3): e210. https://doi.org/10.3989/redc.2018.3.1517

Resumen: Desde la presentación oficial de la fotografía en la Academia de Ciencias de París en el año 1839, la invención de procedimientos, aplicaciones, aparatos y materiales fue constante. La documentación histórica sobre el tema se conserva en la Oficina Española de Patentes y Marcas (OEPM) desde el 27 de marzo de 1826 hasta la actualidad. Es objeto de este artículo el análisis documental de las patentes sobre fotografía concedidas durante un siglo, entre 1839 y 1939 , periodo comprendido entre el invento del daguerrotipo y el final de la Guerra Civil de 1936-1939. La metodología específica se basa en la recuperación de la información desde las bases de datos de la OEPM, que comprenden documentación entre 1826 y 1966. A partir de 85 términos de búsqueda han resultado 973 patentes en el periodo estudiado, de las que se han extraído 221 conceptos clasificados en cinco categorías generales ${ }^{1}$ : Aplicación, Material, Procedimientos, Color y Tecnología. Se han recopilado además los nombres de los solicitantes (1.130) y las fechas de registro de las solicitudes, que se presentan en anexo.

Palabras clave: fotografía; patentes de fotografía; documentación fotográfica; historia de la fotografía; recuperación de la información

\section{Patents related to photography in Spain (1839-1939). Documentary analysis: contents and applicants}

Abstract: Ever since Photography was officially presented for the very first time at the Science Academy of Paris in 1839, the invention of processes, applications, appliances and materials has been continuous. The historic documentation on the subject is kept in the Oficina Española de Patentes y Marcas (OEPM) from March 27th 1826 to the present day. This article focuses on the documentary analysis of those patents related to photography and granted during an entire century, from 1839 to 1939 , a period which begins with the invention of the daguerreotype and ends with the Spanish Civil War, (1936-1939). A specific methodology was set up based on the information obtained from the OEPM data bases, which include documentation from 1826 to 1966. A total of 85 search terms were used, leading to the recovery of 973 patents registered during the period studied, from which a total of 221 concepts have been obtained and classified according to five general categories: Applications, Materials, Processes, Color and Technology. The applicants' names $(1,130)$ and the registration dates of the applications are included as an Appendix.

Keywords: photography; photography patents; photographic documentation; history of photography; information retrieval.

Copyright: ( 2018 CSIC. Este es un artículo de acceso abierto distribuido bajo los términos de la licencia de uso y distribución Creative Commons Reconocimiento 4.0 Internacional (CC BY 4.0). 


\section{INTRODUCCIÓN}

La ciencia se basa en el estudio, en la investigación. Es connatural al ser humano superar los retos de civilizaciones anteriores, por lo que aquello que alguien descubre es punto de partida para nuevo conocimiento. Desde los comienzos de la humanidad se ha reconocido académica y socialmente a los inventores, sin embargo se tardó en registrar las ideas a través de patentes.

El Diccionario de la Real Academia Española define Patente de Invención, como: "Documento en que oficialmente se le reconoce a alguien una invención y los derechos que de ella se derivan". Las patentes son ideas a desarrollar, propuestas con un valor determinado en el país de origen, y en ese espacio geográfico han de desarrollarse. El derecho internacional ha creado los organismos que garantizan su correcto uso, y en el caso de Europa deben ir acompañadas de un instrumento legal que protegerá la invención. La Unión Europea considera que: "Una patente es un título legal de propiedad industrial que otorga a su propietario el derecho exclusivo de explotar una invención comercialmente para un área y tiempo limitados. La patente confiere a su titular el derecho de impedir que otros, entre otras cosas, copien, utilicen o vendan tal invención sin autorización. A cambio del derecho exclusivo de explotación, se publican los detalles técnicos de la invención. La patentabilidad requiere novedad, inventiva y aplicabilidad industrial de la invención" (Eurostat, 2015). Por tanto, son dos los aspectos clave: el derecho exclusivo que impide a otros su uso o venta sin la autorización expresa del inventor, y la innovación, es decir lo que se ofrece como novedoso y de utilidad, aplicable a la industria.

El organismo europeo que rige este sistema es la Oficina Europea de Patentes (OEP), y a nivel mundial la Organización Mundial de la Propiedad Intelectual (OMPI). En España, es la Oficina Española de Patentes y Marcas (OEPM) la encargada del registro y normalización, y se rige por la Ley 24/2015 de 24 de julio de Patentes y Modelos, que garantiza la protección que dispensan y se extiende a todo el territorio nacional. En este ámbito supranacional se desenvuelven las patentes, y las legislaciones de los países han logrado acuerdos de aplicación a nivel europeo y mundial.

Son objeto de estudio en este artículo las patentes sobre fotografía en España en el periodo acotado entre 1839 y 1939, es decir, durante el siglo comprendido entre la invención del daguerrotipo y el final de la Guerra Civil (1936-1939). Los objetivos específicos son: conocer la diversidad y tipología de los contenidos (procedimientos, aplicaciones, tecnología y materiales), así como a los solicitantes (autores y empresas responsables de las patentes), con el fin de aportar nuevos datos a la historia.

Este artículo responde además a los planteamientos del Plan Nacional del Patrimonio Fotográfico del Ministerio de Cultura (2015), que señala entre sus objetivos el fomento de la investigación sobre los diversos aspectos de la gestión del patrimonio fotográfico, apoyando el desarrollo de técnicas innovadoras y buenas prácticas, al tiempo que el desarrollo y promoción de estrategias de sensibilización social para el conocimiento y la valoración del patrimonio fotográfico como documento histórico y como bien cultural.

Sobre el estado de la cuestión hemos de señalar que no hay estudios específicos, con excepción del artículo de Pérez Gallardo (2016) en relación al valor de las patentes del siglo XIX como instrumento para la historia de la fotografía, y las investigaciones de Vega (2014) y Tió (2017) sobre patentes relacionadas con el fotomatón y cámaras automáticas. En cuanto a la legislación de la Propiedad Intelectual y a los registros de patentes, en general, son de referencia los trabajos de Ortiz ViIlajos (1999) y Saiz González (1995, 1996), quien señala en su tesis doctoral Invención, patentes e innovación en España (1759-1878) que entre 1851 y 1878 se registraron 28 privilegios sobre fotografía de un total de 367, datos que ampliamos considerablemente con este trabajo.

Entre las escasas fuentes de época, cabe señalar la nota publicada en la revista La Fotografía (1887) con el título "Patentes fotográficas en Inglaterra", copia de un texto de W. J. Harrison para Photographie News, en el que se indica que entre 1839 y 1885 se registraron en ese país 1.150 , repartidas del siguiente modo: 26 de 1839 a 1853; 585 en la época del colodión (1854-1877); 210 en la etapa del gelatinobromuro (1878-1883), y 329 en la época de aplicación del fotograbado (1884-1885).

En lo que se refiere a la industria es fundamental la monografía Historia de la industria fotográfica española de Carrero de Dios (2001), y entre los estudios históricos con información general sobre la materia se han consultado las obras de Riego (2000) y Vega (2004), ambos sobre el desarrollo de la fotografía en el siglo XIX, y las de Sougez (1994, 2007) y Sánchez Vigil (2013, 2017), con aportaciones específicas sobre las aplicaciones a la ciencia, el arte y la industria.

La estructura del trabajo responde a la recopilación de referencias bibliográficas, el diseño de la base de datos para la recuperación de la información, el proceso de ésta de acuerdo al análisis metodológico que se explica en el capítulo correspondiente, y por último en la presentación y valoración de los resul- 
tados y conclusiones. Como anexo se ha elaborado la relación completa de solicitantes con el tema de la patente, la categoría asignada y la fecha de solicitud.

\section{LA FOTOGRAFÍA EN ESPAÑA (1839-1939)}

Con el fin de contextualizar el desarrollo de la fotografía en el periodo que se acota en la investigación, es importante indicar que mientras en Europa y en Estados Unidos la evolución fue rápida, en España paulatina y, salvo excepciones, con gran retraso en investigación y asociacionismo. El periodista Pedro Barragán escribió en el periódico El Céfiro en 1864 que los fotógrafos españoles carecían de formación y que adolecían de conocimientos en física y química, por lo que no podían entender ni intervenir en los procesos, de ahí que los calificara de "farsantes y explotadores que engañan al público, haciendo el escamoteo de un busto que está muy distante de parecerse al original" (Barragán, 1864).

El 7 de enero de 1839 Louis Jacques Mandé Daguerre presentó oficialmente el daguerrotipo en la Academia de Ciencias de París, dando así a conocer la fotografía. Los estudios históricos sobre la misma siguieron generalmente una metodología basada en la evolución de los procedimientos, aplicaciones y técnicas (Sougez, 1994), y a partir de la invención de la carte de visite por André Adolphe Eugène Disdéri, modelo basado en el soporte, se contempló también a los autores. Hasta finales del siglo XIX los estudios históricos se basaron en los procedimientos, en la aplicación a la ciencia y el arte, y en los soportes (Sánchez Vigil, 2017), relacionados éstos con la actividad en los estudios de fotografía (retratistas de galería).

Desde la década de 1880, con la aparición del fotograbado, hasta mediados de los años veinte el enfoque derivó hacia los contenidos, especialmente a la información (fotoperiodismo) y a la creación (pictorialismo y vanguardia), mientras que los aspectos técnicos industriales quedaron relegados a un segundo plano, con excepción de las cámaras y la óptica.

En el siglo XX la fotografía se consolidó como elemento informativo en la prensa gracias a la proliferación de las grandes revistas ilustradas, tanto de información general como especializada (Mundo Gráfico, La Esfera, Cosmópolis, etc.), con antecedente en Blanco y Negro y Nuevo Mundo, ambas creadas en la última década del siglo XIX, siguiendo los modelos alemanes.

Por todo ello, el estudio de las patentes en el periodo seleccionado es de gran interés, ya que nos permite conocer la evolución de los procedimientos, aplicaciones, tecnologías y materiales desde la perspectiva industrial, punto de vista que, como ya hemos indicado, apenas ha sido contemplado por los fotohistoriadores.

\section{PATENTES DE FOTOGRAFÍA EN ESPAÑA. METODOLOGÍA DEL ANÁLISIS Y RESULTADOS}

Como se ha indicado, son objeto de estudio en este artículo las patentes sobre fotografía registradas en España durante un siglo (1839-1939). La investigación se ha realizado a partir de la información que se ofrece en la web de Historia de la Propiedad Industrial de la Oficina Española de Patentes y Marcas (http://historico.oepm.es), compuesta por cuatro bases de datos: 1. Privilegios (27 de marzo de 1826 a 31 de julio de 1878) $)^{2} ; 2$. Patentes ( 1 agosto de 1878 a 15 febrero de 1940$)^{3} ; 3$. Patentes ( 1 de enero de 1930 a 31 de diciembre de $1966)^{4}$, y 4 . Marcas (18 de noviembre de 1865 a 22 de julio de 1917) ${ }^{5}$.

La OEPM define Privilegio como el conjunto de derechos concedidos por el Estado a un inventor de un nuevo producto o tecnología, y los data desde 1826 hasta el 31 de julio de 1878, fecha en la que se promulgó una nueva ley; las Patentes se presentan como el conjunto de derechos concedidos por el Estado al inventor de un nuevo producto o tecnología, susceptible de ser explotados comercialmente por un tiempo limitado (máximo 20 años), a cambio de la divulgación de la invención. Las Marcas son el símbolo o palabra elegidos para representar el negocio o sus productos, que duran en el tiempo o nunca vencen.

A los efectos del trabajo que nos ocupa todos los registros se considerarán como Patentes, y aunque no son objeto de estudio indicaremos que las Marcas solicitadas y concedidas en el periodo de análisis fueron las 13 que se detallan: 5 de empresas españolas, 6 de Agfa y 2 de Kodak. Las marcas españolas fueron: Gran Fotografía Austriaca de Eduardo de Lete, 15 de octubre de 1904 ( $n^{\circ}$ 11268); Foto Radium de José Blanco Toral, 17 de junio de 1911 ( $n^{\circ}$ 19454); Sello Foto Regalo de Juan Padró Busquets, 13 de junio de 1917 (n 30922); Daguerre (papel fotográfico) de Arte Fotográfico, 12 de mayo de 1916 (no 28652), y Cosmos Fotográfico de Fernández y Carbonell, 29 de agosto de 1903 (n० 10199). Agfa realizó los registros entre 1904 y 1912: cámara Agfa (10904), 4 de junio de 1904; cámara Isolar (10903), 7 de junio de 1904; revelador Rodinal (10902), 7 de junio de 1904; cámara Anschütz (14044), 11 de julio de 1907; cámara Isorapid (18540), 21 de noviembre de 1910, y aparato Kapselblitz (21391), 3 de agosto de 1912. Las marcas de Kodak fueron: papel Solio (7023) y cámara Kodak (7023 bis), ambos registros de 12 de mayo de 1899 . 


\subsection{Metodología del análisis}

Con el fin de recuperar la información en las bases de datos se realizó en primer lugar un listado de términos generales para la búsqueda, que fueron ampliados en función de los sucesivos resultados hasta sumar un total de 85 (Tabla I), incluidos los nombres de algunos autores relacionados con procesos, materiales o aplicaciones, tales como el Conde de Lipa, Jacob Wothly, Jean Laurent, Alfonso Roswag o José Martínez Sánchez (éstos dos últimos yerno y socio de Laurent respectivamente).

La búsqueda fue exhaustiva con el fin de recuperar el máximo de patentes, por ello el 34,11\% de los 85 términos aplicados no dieron resultados, es decir que la base no respondió a los 29 términos que se indican: Agfacolor, Ambrotipo, Americana (tarjeta), Autocromo, Autorretrato, Baño de paro, Boudoir (tarjeta), Cabinet (tarjeta), Carte de visite, Cortinilla, Daguerrotipo, Estudio fotográfico, Fijador, Fotocolor, Fotomatón, Gabinete fotográfico, Hiposulfito, Imperial (tarjeta), Kodachrome, Kodacolor, Lente, Martínez de Hebert, Martínez Sánchez, Papel leptográfico, Placa de vidrio, Promenade (tarjeta), Tarjeta de visita y Teleobjetivo.

Sobre la configuración de la base de datos de la OEPM, hemos de indicar que no contempla la normalización de los términos en masculino-femenino y singular-plural, lo que obliga a una exhaustiva búsqueda con todas las variaciones posibles, además de realizar comparativas para la selección. Por ejemplo los términos "Foto" y "Fotos" dan como resultado 69 y 4 registros respectivamente; del término "fotográfica" resultan 162 registros, de "fotográfico" 196, de "fotográficas" 423 y de "fotográficos" 227. De todos ellos solo una parte coinciden. Otra consideración es que los términos deben ser concretos, es decir que por el prefijo "foto" no se obtienen los compuestos o derivados de esa palabra, teniendo que buscar además por "fotografía" y "fotográfico".

Con el fin de estructurar y procesar la información resultante de la búsqueda se diseñó una base de datos con los siguientes campos:

1. Número currens (número de orden)

2. Término: término de búsqueda para la localización de la patente

3. Categoría: clasificación específica determinada (Aplicación, Color, Material, Procedimiento, Tecnología)

4. Tipología del documento (establecida por la OEPM): Privilegio, Patente

5. Subtipo (establecido por la OEPM): Patente de invención, Invención, Patente de introducción, Introducción, Certificado de adición, Duplicado de patente de invención.

6. Descripción: Breve descripción del contenido

7. Número de expediente: otorgado por la OEPM

8. Fecha (Año/Mes/Día)

9. Solicitante (persona física o jurídica)

10. Observaciones (Notas)

Tabla I. Patentes sobre fotografía. Términos de búsqueda

\begin{tabular}{|c|c|c|c|c|}
\hline Agfa & Carte de visite & Fotograbado & Laboratorio & Positivo \\
\hline Agfacolor & Cliché/s & Fotografía/as & Laurent, Jean & Procedimiento carbón \\
\hline Álbum/es & Colodión & Fotográfica-o/as/os & Lente & Promenade (tarjeta) \\
\hline Albúmina & Cortinilla & Fotógrafo/s & Lipa, Conde de & Retícula \\
\hline Americana (tarjeta) & Daguerrotipo & Fotomatón & Magnesio & Retrato/s \\
\hline Ampliadora & Diapositiva & Fotomecánica & Máquina & Revelado/r \\
\hline Autocromo & Diafragma/as & Fotómetro & Martínez Hebert, P. & Rollo \\
\hline Autorretrato & Emulsión & Gabinete & Martínez Sánchez, J. & Roswag, Alfonso \\
\hline Baño de paro & Ambrotipo & Galería/s & Negativo & Tarjeta Álbum \\
\hline Boudoir (tarjeta) & Estereoscopía & Gelatina & Negativo cristal & Tarjeta de visita/s \\
\hline Bromóleo & Estereoscópica/o & Gelatinobromuro & Negativo de cristal & Tarjeta fotográfica \\
\hline Bromuro de plata & Estereoscopo & Hiposulfito & Objetivo/s & Tarjeta postal \\
\hline Cabinet (tarjeta) & Estudio fotográfico & Imagen & Obturador & Telémetro \\
\hline Cámara/as & Fijador & Imperial (tarjeta) & Papel fotográfico & Teleobjetivo \\
\hline Cámara fotográfica & Flash & Kodachrome & Papel leptográfico & Transparencia \\
\hline Carbón & Foto/os & Kodacolor & Placa de cristal & Wothly, Jacob \\
\hline Carrete & Fotocolor & Kodak & Placa de vidrio & Zoom \\
\hline
\end{tabular}


Las categorías (Campo 3) se fueron determinando a posteriori, una vez revisado gran parte del contenido y teniendo en cuenta su descripción (Campo 6). Son las siguientes:

- Aplicación: desarrollo de los procedimientos mediante su uso y aplicación a la ciencia, el arte, la documentación y/o la información (medicina, reproducción de obras de arte, fotograbado, impresión, tejidos, etc.)

- Color: patentes específicas sobre la fotografía en color y el coloreado de positivos y negativos, cualquiera que sea el procedimiento, aplicación, tecnología o material empleado.

- Material: elementos necesarios para realizar las tareas con la tecnología adecuada, para su presentación y conservación (películas, papeles, álbumes, soportes, tarjetas, chasis, carretes, etc.)

- Procedimientos: procesos y fórmulas para la formación y obtención de la imagen (albúmina, ferrotipos, fijados, revelados, emulsiones, virajes, etc.)

- Tecnología: conjunto de instrumentos y aparatos necesarios para la toma de la imagen (cámaras, ampliadoras, equipos de iluminación, secadoras, fotomatones, objetivos, obturadores, etc.).

\subsection{Resultados}

Los resultados de la búsqueda en todas las bases de datos de la OEPM, una vez discriminados, son 1.786 patentes relacionadas directamente con la fotografía. En el periodo de estudio (1839-1939) y tras el análisis de los contenidos son 973 (199 de empresas y 774 de particulares), distribuidas en 221 temas específicos con un segundo nivel en 12 casos. De acuerdo a las cinco categorías generales, las patentes son: Aplicación 110, Color 142, Material 158, Procedimientos 214, y Tecnología 349 (Tabla II).

Tabla II. Patentes sobre fotografía (1839-1939)

\begin{tabular}{|c|c|c|}
\hline Categoría & No patentes & Porcentaje \\
\hline Aplicación & 110 & 11,32 \\
\hline Color & 142 & 14,60 \\
\hline Material & 158 & 16,26 \\
\hline Procedimientos & 214 & 22,02 \\
\hline Tecnología & 349 & 35,80 \\
\hline TOTAL & 973 & 100 \\
\hline
\end{tabular}

En relación a los datos resultantes, y según comentamos en el estado de la cuestión, Patricio Sáiz (1996) indicaba que entre 1851 y 1878 se registraron 28 privilegios, sin embargo, en la investigación realizada para este artículo, son 41 los documentos fechados entre 1854 y 1878.

Dentro de cada categoría general se han registrado temas específicos (Tabla III). De la categoría Aplicación han resultado 30 temas, de Color 30, de Material 16, de Procedimientos 76 y de Tecnología 54. En cada tema se indica entre paréntesis el número de veces que aparece. Se ha considerado además una subdivisión (señalada en cursiva) en 13 casos: Aplicación (Metal); Color (Impresión, Placas, Sistemas); Material (Papel, Placas, Soportes); Procedimientos (Positivo, Rayos); Tecnología (Aparatos, Cámaras, Prensa, Proyector).

En la categoría Aplicación los temas con mayor número de registros son Esmaltes, Foto aérea, Fotograbado, Identificación, Impresión, Metal, Tejidos y Abanicos. Sobre el Color los mayores registros se relacionan con el coloreado de las fotografías en blanco y negro y con los sistemas generales para el desarrollo de métodos técnicos. Por lo que respecta al material, los principales registros se reparten entre los Papeles y Películas en sus diferentes tecnologías, así como los Soportes (tarjetas de todo tipo) y los Álbumes. Las patentes sobre Procedimientos son mayoría en el tema de las Emulsiones, Reproducción y Revelado. Por último, en cuanto a la Tecnología, los principales apartados son los de Aparatos y Cámaras, con gran diferencia del resto.

Una vez conocido el número total y la diversidad de patentes resulta interesante saber la distribución en los siglos XIX y XX para entender el desarrollo de la fotografía (Tabla IV). Se observa así claramente la evolución, que se multiplicó considerablemente en todos los casos, excepto en la categoría Aplicación donde se produjo un importante descenso, pasando de 85 a 25 registros. En la categoría Color la evolución coincide con la presentación y comercialización de los autocromos por los hermanos Lumière a partir de $1903^{6}$.

El primer registro en la OEPM fue el Privilegio del francés M. R. Laverdet (1138) sobre un "Sistema de fotografía con el cual se reproducen los objetos con toda exactitud", fechado el 20 de febrero de 1854. Los primeros españoles los realizó Jean Laurent sobre el coloreado de retratos y vistas (1321 y 1474), fechados el 20 de julio de 1855 y el 29 de agosto de 1859. Posteriormente patentaría la aplicación de la foto a los abanicos (3026) el 12 de diciembre de 1864. En la década de los sesenta se concedieron otras tres solicitudes a Joaquín Hernández de Tejada, sobre "Iluminación al óleo de 
toda clase de fotografías, litografías y grabados" (1548), el 2 de febrero de 1857, José Sierra Payba sobre un "Método de hacer retratos en tarjeta de sociedad y cartas de correspondencia mediante la fotografía" (2679), el 22 de mayo de 1863, y Joaquín Sánchez Vasco sobre un "Procedimiento para retratar por medio de la fotografía en toda clase de tejidos de hilo" (3043), el 22 de enero de 1865. La última patente en el periodo de análisis data del 22 de diciembre de 1939 y se trata de un "Procedimiento para obtener fotografías no estereoscópicas que dan la sensación de relieve" (148956).

Tabla III. Categorías de las patentes

\begin{tabular}{|l|l|l|l|}
\hline ApLICACIÓN (31 temas/110 patentes) \\
\hline Abanicos (5) & Foto espejo (4) & Mármol (2) & Reproducción (4) \\
\hline Anáglifos (1) & Foto panorámica (1) & Metal (9) & Retratos (3) \\
\hline Anuncio (4) & Foto recorte (1) & -Metaline (1) & Tejidos (8) \\
\hline Cartografía (2) & Fotograbado (6) & Perrito maravilloso (1) & Telefotografía (1) \\
\hline Cristal/Opal (3) & Fotomecánica (1) & Pintura y grabado (1) & Tríptico (1) \\
\hline Cuero (1) & Grabado (1) & Plásticos (1) & Varios (2) \\
\hline Esmalte (7) & Identificación (9) & Porcelana (6) & \\
\hline Foto aérea (8) & Impresión (14) & Repiés (1) \\
\hline
\end{tabular}

\section{Color (30 temas/142 patentes)}

\begin{tabular}{|c|c|c|c|}
\hline Aparato (2) & Impresión (6) & Pirocromografía (1) & Revelado (3) \\
\hline Autocromas (1) & -Impresión (5) & Placas (4) & Sistemas (58) \\
\hline Bicromía (1) & -Luminosa (1) & -Placas (1) & -Sistemas (53) \\
\hline Coloreado (12) & Maquina (1) & -Placas Lumiere (1) & -Fotonatura (1) \\
\hline Copias (1) & Material (7) & -Placas sensibles (2) & -Lini-color (1) \\
\hline Cronofotografía (1) & Multicolor (2) & Policromía (3) & -Modern Style (1) \\
\hline Emulsión (1) & Negativos (4) & Positivos (2) & -Oleofotografía (1) \\
\hline Filtro (2) & Óptica (2) & Pruebas (1) & -Radiotint (1) \\
\hline Fondos (1) & Pantalla (5) & Reproducciones (1) & Sustracción (1) \\
\hline \multirow[t]{2}{*}{ Fotocromos (1) } & Película (4) & Retratos (4) & Transparencia (2) \\
\hline & & & Tricromía (8) \\
\hline \multicolumn{4}{|c|}{ MATeRIAL (16 temas/158 patentes) } \\
\hline Álbum (8) & Film-pack (2) & -Pigmentario (1) & Sello de caucho (1) \\
\hline Anunciador (1) & Fondo (1) & -Porcelana (1) & Soportes (37) \\
\hline Carretes (2) & Papel (25) & -Roche (1) & -Soporte (2) \\
\hline Cartón (1) & -Papel (18) & Película (26) & -Aluminio (1) \\
\hline Chasis (13) & -Adherente (1) & Placas (18) & -Carte de visite (4) \\
\hline Cliché (19) & -Aterciopelado (1) & -Placas (11) & -Tarjetas (11) \\
\hline Cubeta (2) & -Bromuro (1) & -Autorreveladora (1) & Tarjetas postales (19) \\
\hline Estuches (2) & -Charolado (1) & -Secas (6) & \\
\hline
\end{tabular}

\begin{tabular}{|l|l|l|l|}
\hline \multicolumn{4}{|l|}{ Procedimientos (76 temas/ 214 patentes) } \\
\hline Albumina (2) & Fondos (2) & Fotominiatura (1) & Realidad (1) \\
\hline Ampliaciones (1) & Fosforescente (1) & Fototipografía (1) & Reflexión (1) \\
\hline Anotaciones (1) & Foto brillo (1) & Grabado (2) & Relieve (17) \\
\hline Calcografía (1) & Foto con imágenes (1) & Imagen continua (3) & Reproducción (24) \\
\hline Carbón (3) & Foto inalterable (1) & Imagen contrastada (1) & Retoque (3) \\
\hline
\end{tabular}




\begin{tabular}{|c|c|c|c|}
\hline Caricaturas (3) & Foto invulnerable (1) & Imágenes (2) & Retrato (5) \\
\hline Celulosa (1) & Foto mágica (1) & Impresión (3) & Revelado (28) \\
\hline Contraste (1) & Foto microscópica (1) & Inversión (1) & Siluetas (1) \\
\hline Copias (4) & Foto nocturna (1) & Litografía (1) & Superposición (1) \\
\hline Diazofoto (1) & Foto rápida (2) & Movimiento (1) & Tintas (1) \\
\hline Emulsión (23) & Foto reticulada (1) & Negativos teñidos (1) & Toma de fotos (1) \\
\hline Esmalte (1) & Foto sin plata (1) & Nitratos revelado (1) & Tonos (1) \\
\hline Esmalte laca (1) & Foto vistas (1) & Oscuridad (1) & Trama (1) \\
\hline Estarcido (1) & Fotoarquetipia (1) & Pegado (3) & Transformación (1) \\
\hline Estereoscopia (2) & Fotocelina (1) & Positivos (7) & Transmisión (1) \\
\hline Estereosíntesis (1) & Fotocromo (2) & -Positivo bicolor (1) & Transparencia (3) \\
\hline Exposición (1) & Fotodecoracion (1) & Proyector diapositiva (1) & Viraje(2) \\
\hline Fabricación (1) & Fotoescultura (6) & Pruebas (5) & Whothlytipia (1) \\
\hline Ferrotipo (2) & Fotogligo (1) & Rayos (2) & \\
\hline Fijado (5) & Fotolitografía (1) & -Ultravioleta (1) & \\
\hline \multicolumn{4}{|c|}{ TECNOLOGÍA (54 temas/349 patentes) } \\
\hline Almacén (1) & -Plegable (1) & -Plegable (1) & Montaje (1) \\
\hline Ampliadora (9) & -Pratic (2) & - Vistas animadas (3) & Negativos (2) \\
\hline Aparatos (103) & -Prensa (2) & Cartógrafo (1) & Objetivo (5) \\
\hline -Sin identificar (22) & -Proyección (2) & Coche artístico (1) & Obturador (8) \\
\hline -Automáticos (36) & -Reproducción (4) & Cromorelieve (1) & Óptica (7) \\
\hline -Con reflector (1) & -Revelado (8) & Cubeta revelado $(1)$ & Oscilador (1) \\
\hline -Contactos (1) & -Tiraje (3) & Desvanecedor (1) & Pantallas (3) \\
\hline -Con escamoteo (1) & -Tridimensional (1) & Diafragma (2) & Perfeccionamiento (1) \\
\hline -Efecto (1) & Báscula (1) & Disparador (2) & Pinzas graduables (1) \\
\hline -Esférico (1) & Bastidor (2) & Dispositivo (1) & Planchas (3) \\
\hline -Estroboscópico (1) & Cámaras (65) & Esmaltadora (2) & Portaplacas (3) \\
\hline -Exposición (1) & -Cámara (34) & Espejos (1) & Prensa (9) \\
\hline -Foto indivisible (1) & -Automática (2) & Estereoscopia (20) & -Prensa rotativa (1) \\
\hline -Foto serie (1) & -Deformación (1) & Foto ambulante (1) & Prismas (1) \\
\hline -Foto cinematográfico (2) & -Enfoque (1) & Foto indirecta (1) & Producción (4) \\
\hline -Grafoscopio (1) & -Espía (1) & Foto reformada (1) & Proyector (22) \\
\hline -Hemeráscopo (1) & -Estereoscópica (8) & Fotominiatura (1) & -Diapositiva (2) \\
\hline -Imagen monocroma (1) & -Estuche (1) & Fotos alteradas (1) & Recortadora (1) \\
\hline -Impresión (1) & -Foto aérea (2) & Fotos positivas (1) & Retoque (1) \\
\hline -Impresor (1) & -Foto animada (5) & Fotos varias (1) & Secadora (5) \\
\hline -Instantáneo (1) & -Foto múltiple (1) & Fototelegrafía (1) & Tarjeta postal (1) \\
\hline -Lavado (1) & -Fotogramas (1) & Iluminación (23) & Telefotografía (16) \\
\hline -Microfoto (1) & -Galería (1) & Laboratorio (1) & Telegrafía (1) \\
\hline -Miniatura (1) & -Laboratorio (1) & Máquina copias (1) & Telestereógrafo (1) \\
\hline -Montaje (1) & -Oftalmología (1) & Marcador (1) & Trípode (1) \\
\hline -Panorámico (1) & -Panorámica (2) & Medición de luz (1) & Visor (1) \\
\hline
\end{tabular}


Tabla IV. Patentes sobre fotografía (1839-1939)

\begin{tabular}{|l|c|c|}
\hline Categoría & $\begin{array}{c}\text { Siglo XIX } \\
\mathbf{1 8 3 9 - 1 9 0 0}\end{array}$ & $\begin{array}{c}\text { Siglo XX } \\
\mathbf{1 9 0 1 - 1 9 3 9}\end{array}$ \\
\hline Aplicación & 85 & 25 \\
\hline Color & 27 & 115 \\
\hline Material & 37 & 121 \\
\hline Procedimientos & 47 & 167 \\
\hline Tecnología TOTAL & 55 & 294 \\
\hline \multicolumn{2}{|r|}{251} & 722 \\
\hline
\end{tabular}

En lo que se refiere al color, además de las patentes citadas fueron pioneras: "Sistema para dar a los retratos un doble o triple fondo y un colorido permanente" (2069), de Ramón Valls y Benavente, 22 de enero de 1863, y "Proceder por el cual se consigue la pintura en la fotografía con un colorido que representa a la verdadera imagen" (4419) de Pedro Vila Sebastiá, 15 de noviembre de 1867. Las tres últimas sobre color fueron presentadas por las empresas Kodak (una) y Farberindustrie (dos), la primera sobre "Mejoras en los métodos de fotografía en colores" (139133), 27 de julio de 1935, y las otras dos con los títulos "Procedimiento para obtener fotografía de varios colores" (141845), 31 de marzo de 1936, y "Obtención de imágenes de color por revelado en color" (142661), 23 de junio de 1936.

Durante la Segunda República (abril de 1931 a julio de 1936) se solicitaron 129 patentes: 9 sobre Aplicación, 16 sobre Color, 12 de Material, 40 de Procedimientos y 51 de Tecnología. De ellas 13 fueron presentadas por la empresa alemana I. G. Farbenindustrie, de la que formaba parte Agfa, en su mayoría relacionadas con las emulsiones y los líquidos de revelado.

En la Guerra Civil, entre julio de 1936 y finales de $1939^{7}$, se registraron 50 patentes: 25 sobre Color, 10 de Procedimientos, 7 de Tecnología, 6 de Material y 2 sobre Aplicación (Tabla V). Los solicitantes españoles fueron 19 y 31 los extranjeros (23 de I. G. Farbenindustrie, en su mayoría sobre procedimientos en color). Como se observa, los mayores registros fueron sobre Color y Procedimientos, mientras que de Tecnología, Material y Aplicación apenas se presentaron solicitudes. Entre las patentes españolas señalamos por su temática las ocho siguientes: "Aparato para fotografías indirectas" de Juan Munuera Paradís (142970), 6 de agosto de 1936; "Produccion de carretes con bandas sensibles", de Juan Trilla Buxeda (143799), 3 de julio de 1937; "Foto estereoscópica", de Valentín Toscas Fargas (143857), 18 de agosto de
1937; "Perfeccionamiento en los aparatos fotográficos automáticos", de José Vallés Rovira (143917), 21 de septiembre de 1937; "Procedimiento químico para la reproducción de fotografías" de Manuel Pérez Carbonell (144126), 30 de junio de 1938; "Procedimiento para la reflexión de imágenes" de Manuel Valentí Gallart (145244), 10 de octubre de 1938; "Positivas fotográficas opacas" de José de la Peña Baláns (144253), 28 de diciembre de 1938, y "Fabricación de Roll-film y Film-packs", de Joaquín Tort Mensa (146586), 10 de febrero de 1939.

Por lo que respecta a los solicitantes, las patentes fueron registradas por 1.131 personas físicas y jurídicas, tanto españolas como extranjeras: 837 fueron solicitantes únicos, 122 documentos fueron firmados por dos personas o empresas, 13 por tres y 2 por seis. De éstas últimas una fue sobre "Perfeccionamiento de máquinas fotográficas automáticas" (13540) de Pedro Cabanach, Francisco Güell, Miguel Petit, Ramón Fábrega, Marcelino Fábrega y Juan Güell Bergés, fechada el 14 de julio de 1892, y otra sobre "Colodión" de Rosa Bulbena y sus cinco hijos a la que nos referimos más adelante (15962) al tratar de las patentes solicitadas por mujeres.

Aunque la mayoría eran industriales, es decir, fabricantes de materiales o de productos químicos, es importante señalar que fueron varios los autores de prestigio (retratistas, paisajistas y documentalistas, etc.) que patentaron inventos, entre ellos Jean Laurent (abanicos, 3026; coloreado, 132; retratos, 1474), Conde de Lipa (cartes de visite, 4300), Pau Audouard (cámaras, 45145, 42635), Rafael Areñas (fotos en la oscuridad, 114264), José Baltá (iluminación, 67854), Lucas Cepero (placas y papel, 26940), Christian Franzen (soporte cristal, 84029), J. L. Mariani (color, 147077), Sierra Payba (cartes de visite, 2679, 4084) o Alfredo Truán (5808).

Es significativo el reducido número de patentes solicitadas por mujeres, solo cuatro. La más antigua está fechada el 16 de febrero de 1909 sobre colodión cantaridado (15962) y la registraron Rosa Bulbena, viuda del doctor José Masó Arumi, y sus cinco hijos: Monserrat, Álvaro, María Teresa, Juan y José Luis Masó Bulbena. Otras dos se presentaron en la segunda década del siglo XX: "Procedimiento para obtener papel fotográfico positivo" (53168), 31 de mayo de 1912, de Teresa del Fabro, y "Procedimiento para disparar los obturadores fotográfi$\cos ^{\prime \prime}$ (46818) de Katharina Verini, 27 de noviembre de 1919. La cuarta y última está fechada en Bilbao pocos días antes del final de la Guerra Civil, el 24 de marzo de 1939. La firmó Manuela Crespo Fornell, entonces con domicilio en Málaga y a partir de 1940 en el número 11 de la calle Martínez Campos de Madrid. Se trata de un "Método para aplicar la fotografía al mármol y a la piedra" (146707). 
Tabla V. Patentes durante la Guerra Civil (julio 1936-diciembre 1939)

\begin{tabular}{|c|c|c|c|c|c|}
\hline & 1936 & 1937 & 1938 & 1939 & TOTAL \\
\hline Aplicación & & & & 2 & 2 \\
\hline Color & 4 & 6 & 11 & 4 & 25 \\
\hline Material & & 1 & & 5 & 6 \\
\hline Procedimientos & 1 & 2 & 3 & 4 & 10 \\
\hline Tecnología & 1 & 2 & 1 & 3 & 7 \\
\hline TOTAL & 6 & 11 & 15 & 18 & 50 \\
\hline
\end{tabular}

\section{CONCLUSIONES}

A partir de los resultados obtenidos y del consiguiente análisis de los mismos, se concluye que se aportan datos para la historia de la fotografía española desde el punto de vista industrial, aspecto muy poco estudiado. En ese sentido la información es de gran interés para el conocimiento y estudio de la industria, en general, y de la fotográfica en particular.

Se considera que las 973 patentes sobre fotografía registradas entre 1839 y 1939 son pocas para un periodo de tiempo tan amplio, sobre todo si tenemos en cuenta las características propias de la materia y sus diferentes aspectos: aplicaciones, procedimientos, tecnología y materiales.

Dado que las bases de datos de la OEPM recogen solicitudes desde el año 1826, entendemos que antes de 1854, año en que se efectuó el primer registro, no se registraron inventos relacionados con la fotografía, lo que no significa que no se realizaran sino que no quedó constancia oficial de los mismos. Se observa así mismo una clara diferencia entre los registros del siglo XIX (251) y del siglo XX (722), dato que concuerda con el desinterés de los gobiernos decimonónicos por el desarrollo de esta

\section{NOTAS}

1. Para determinar las categorías se ha contado con la colaboración de dos profesionales y artistas de la fotografía: Luis Castelo, profesor de la Facultad de Bellas Artes de la Universidad Complutense de Madrid, y Rubén Morales, conservador-restaurador de patrimonio fotográfico, a quienes agradecemos su colaboración.

2. Base de datos elaborada a partir de la investigación de Patricio Sáiz para su tesis doctoral: Invención, patentes e innovación en España (1759-1878).

3. Base de datos elaborada por el equipo de investigación dirigido por Patricio Sáiz, Francisco Cayón y Francisco Llorens. Universidad Autónoma de Madrid. Convenio de colaboración OEPM-UAM.

4. Base de datos elaborada por el equipo de investigación dirigido por Antonio Hidalgo de la Universidad Politéc- industria, todo ello teniendo en cuenta que se vivió entre convulsiones políticas y guerras civiles.

De los resultados se concluye también que los inventos sobre la tecnología, es decir, sobre los aparatos (cámaras, ampliadoras, proyectores, etc.) y los materiales necesarios para su uso (placas, películas, papel, etc.) fueron los más numerosos (506 de 973, $52.10 \%$ del total), seguidos de los procedimientos, incluidos los de color (356 de 973, 36.60\%), y por último de las aplicaciones (110 de 973, 11.30\%).

Se dan a conocer los nombres de 1.131 solicitantes (particulares y empresas), muchos de ellos profesionales y entidades de gran prestigio y relevancia social, tales como los citados conde de Lipa, Jean Laurent, Sierra Payba, Pau Audouard o Christian Franzen, así como Agfa, Kodak o I. G. Farbenindustrie, datos que hasta el momento no han sido considerados en las monografías sobre la materia, por lo que son de gran interés.

Por último, gracias a la investigación hemos sabido que, oficialmente, el papel de la mujer en cuanto al registro de patentes no fue relevante, ya que en el periodo estudiado solo se registraron cuatro con grandes intervalos de tiempo en los años 1909, 1912,1919 y 1939.

nica de Madrid (2002 y 2003). Proyecto: Análisis estadístico de datos básicos de patentes como indicadores de innovación: 1930-1966. Figura la fecha 1930-1966, si bien los datos corresponden al periodo 1941-1966.

5. Base de datos en construcción por el equipo de investigación dirigido por Patricio Sáiz, Francisco Cayón y Francisco Llorens. Universidad Autónoma de Madrid. Convenio de colaboración OEPM-UAM.

6. Los autocromos eran placas positivas de vidrio en color. Fueron patentados por los hermanos Lumière en 1903 y comercializados a partir de 1907. A mediados de los años treinta fueron sustituidos por las películas en rollo.

7. Aunque la Guerra Civil finalizó en marzo de 1939, se ha considerado el año completo. 


\section{REFERENCIAS}

Barragán Guerra, P. (1864). Fotografía. Su pasado, su presente y su porvenir. El Céfiro, 5 de mayo.

Carrero de Dios, M. (2001). Historia de la industria fotográfica española. Girona: CCG Ediciones, 152 pp.

Diccionario de la Lengua Española. Patente. http://dle. rae.es/?w=diccionario [Consulta: 17/06/2017].

Eurostat (2015). Archive: Patent statistics. http:// ec.europa.eu/eurostat/ [Consulta: 12/06/2017].

Oficina Española de Patentes y Marcas (OEPM). Web de Historia de la Propiedad Industrial. http://historico. oepm.es [Consulta: Enero-Septiembre 2017].

Ortiz Villajos, J. M. (1999). Tecnología y desarrollo económico en la historia contemporánea: estudio de las patentes registradas en España entre 1882 y 1935. Madrid: Oficina Española de Patentes y Marcas.

Pérez Gallardo, H. (2016). Patentes fotográficas en el siglo XIX: instrumento del conocimiento técnico para la Historia de la fotografía. En: González Redondo, F. (Coordinador). Ciencia y técnica entre la paz y la guerra: 1714, 1814, 1914, Vol. 2, pp. 1265-1272.

Plan Nacional de Conservación del Patrimonio Fotográfico (2015). Madrid: Ministerio de Educación, Cultura y Deporte, 100 pp.

Riego, B. (2000). La introducción de la fotografía en España. Un reto científico y cultural. Girona: CGC Editores, $256 \mathrm{pp}$.

Sáiz González, J. P. (1995). Propiedad industrial y revolución liberal. Historia del sistema español de patentes (1759-1929). Madrid: Oficina Española de Patentes y Marcas, Ministerio de Industria y Energía, 202 pp.

Sáiz González, J. P. (1996). Invención, patentes e innovación en España (1759-1878). Tesis doctoral. Madrid: Universidad Autónoma de Madrid, 300 pp.

Sánchez Vigil, J. M. (2017). La fotografía en sus reversos. La puerta de atrás. Madrid: Universidad Complutense de Madrid, $160 \mathrm{pp}$.

Sánchez Vigil, J. M. (2013). La fotografía en España. Otra vuelta de tuerca. Gijón: Trea, 496 pp.

Sougez, M. L. (coord.) (2007). Historia general de la fotografía. Madrid: Cátedra, 856 pp.

Sougez, M. L. (1994). Historia de la fotografía (5a Ed.). Madrid: Cátedra, 452 pp.

Tió, S. (2017). El fracaso de The Automatic Photograph Company, origen de la cámara minutera. En Hernández Latas, J. A. (coord.). I Jornadas sobre investigación en la historia de la fotografía, 1839-1939. Un siglo de fotografía. Zaragoza: Institución Fernando el Católico, p. 309-320.

Vega, C. (2014). Orígenes del fotomatón en España, 1888-1929. Revista General de Información y Documentación, 24 (2), 305-341.

Vega, C. (2004). El ojo en la mano. La mirada fotográfica en el siglo XIX. Girona: CCG Editores, 144 pp.

\section{ANEXO}

Patentes de fotografía: Se indican los solicitantes con el siguiente orden:

Nombre; Categoría; Número de patente; Año

(Categorías: A: Aplicación; C: Color; M: Material; P: Procedimiento; T: Tecnología)

Aberastain, A.; T-Aparato. Contactos; 96771; 1926

Abreu, Á. J.; T-Óptica; 35158; 1904

Abreu, Á. J.; T-Óptica; 36813; 1905

Adolfo de Porta y Cía.; A-Esmaltes; 36024; 1905

Aguiló, F.; Albert, J.; A-Tejidos; 56178; 1913

Ahrle, F.; Krebe, W.; P-Foto brillo; 108007; 1928

Akerlund, A.; T-Diafragma/Roentgen; 83969; 1922

Alberca, M.; A-Vistas; 80558; 1922

Albiñana, J. \& Julia, E.; A-Esmalte/Porcelana; 4129; 1866

Aldabó, J.: P-Reproducción; 13750; 1935

Alfredi, G.; C-Impresión; 1116702; 1930

Allen, A. R. ; Bourne, F.H.; Allen, R.; T-Aparato; 112810; 1929

Almeida, P.; T-Iluminación; 137223; 1935

Almenara, E.; A-Identificación; 64095; 1917

Alonso, M.; A-Foto espejo; 60487; 1915

Alonso, S.; A-Perrito maravilloso; 9073; 1888

Álvarez, T. ; P-Transformación; 104584; 1927

Amer, F.; M-Película; 147303; 1939

Amer, F.; M-Película; 147680; 1939

Amer Esteve, F.; Llobet, S.; M-Papel; 31010; 1903

American Machine \& Foundry Co. T-Cámara; 97640; 1926

American Phototure Co.; T-Aparatos; 103872; 1927

Amira Trust; P-Emulsión; 123931; 1931

André \&Lieutier; Girandy; T-Aparato automático; 1577; 1894

André \&Lieutier; Girandy; T-Aparato automático; 16748; 1894

Andresen, M.; P-Revelado-fijado; 9403; 1889

Animated Picture; T-Cámara; 73637; 1920

Aparicio, C.; P-Reproducción impreso; 139256; 1935

Ara, J.; A-Metal/Madera; 89292; 1924

Aramburu, R.; M-Sello de caucho; 7430; 1887

Aramburu, R.; P-Ferrotipo; 16312; 1894

Aramburu, R.; P-Fotoescultura; 13604; 1892

Arce, P.; P-Revelado; 84439; 1923

Areñas, R.; P-Oscuridad; 114264; 1929

Ariño, J.; A-Varios; 133913; 1934

Arisó, G.; Ruiz, Á.; T-Aparato; 69986; 1919

Arisó, G.; Ruíz, Á.; T-Aparato; 71172; 1919

Arnau, A.; T-Medición de luz; 26887; 1900

Arnulf, A.; Bonneau, P.; C-Policromía; 133664; 1934

Arte Fotográfico; P-Revelado; 62303; 1916

Artigas, V.; M-Papel; 39765; 1906

Assche, N.; T-Desvanecedor; 96541; 1926

Aubell, W.; M-Papel; 63976; 1917

Audouard, P.; Lleo, A.; Baradat, C.; T-Aparato fotocinematografía; 42635; 1908

Audouard, P.; Lleo, A.; Baradat, C.; T-Cámara; 45145; 1909

Aymat, L.; A-Identificación; 112729; 1929

Aymat, L.; A-Identificación; 119228; 1930 
Aymat, L.; P-Emulsión; 119798; 1930

Aymat, L.; P-Foto invulnerable; 119859; 1930

Bacigalupi Internazionale Clichés; M-Cliché; 40732; 1907

Baese, C.; A-Plástico; 29560; 1902

Bailey, E.; T-Aparato automático; 86070; 1923

Baïz, B.; T-Ampliadora; 85264; 1923

Ballesteros, S.; M-Tarjeta postal; 62259; 1916

Baltá, J.; T-Adaptador placas; 69447; 1919

Baltá, J.; T-Iluminación; 67854; 1918

Baradat, C.; Bosch, F.; T-Aparato automático; 49584; 1910

Barceló, J.; T-Proyector; 135153; 1934

Bárcena, F.; T-Proyector; 106832; 1928

Bárcena, F.; T-Proyector; 91587; 1924

Bárcena, F.; T-Proyector; 93096; 1925

Bárcena, F.; T-Proyector; 93329; 1925

Bárcena, R.; M-Tarjeta postal Argos; 47293; 1910

Bargués, E. y Co.; T-Aparato automático; 65140; 1917

Bargués, E. y Co.; T-Cámara laboratorio; 64922; 1917

Barguño, J. A-Producción; 97782; 1926

Barguño, J.; P-Retoque; 123681; 1981

Barguño, J.; P-Retoque; 96704; 1926

Barrau, A.; T-Proyector; 51451; 1911

Barricelli, M.; P-Fotoarquetipia; 33994; 1904

Barros, E.; Rodenburg, E.; T-Cámara estereo; 139453; 1935

Baschstein, R.; Enge, B.; A-Foto aérea; 40326; 1907

Baschstein, R.; Enge, B.; T-Aparato esférico; 40325; 1907

Bassani, Procedess; A-Fotomecánica; 90955; 1924

Basso, E.; T-Proyector; 115254; 1929

Beidler, G. Ch.; T-Aparato; 47280; 1910

Bekk \& Haulten Ch. Fabrik; P-Emulsión; 148546; 1936

Belin, E. Telegraphes; P-Transmisión; 56344; 1913

Belin, E. Telegraphes; T-Cámara foto animada; 75328; 1920

Belin, E. Telegraphes; T-Telefotografía; 56129; 1913

Belin, E.; T-Telefotografía; 90614; 1924

Belin, E.; T-Telestereógrafo; 42409; 1908

Bell Teléfonos; T-Telefotografía; 90916; 1924

Bell Teléfonos; T-Telefotografía; 95662; 1925

Bello, J.; P-Grabado; 1996; 1881

Bellver ,J.; P-Foto miniatura; 85789; 1923

Bellver, J.; T-Iluminación; 37018; 1905

Beltrá, P.; A-Marmol; 71041; 1919

Bennett, C. W. ; P-Revelado; 139802; 19335

Bernardi, A.; C-Sistemas; 110622; 1928

Berriatua, J.; T-Aparato automático; 110662, 1919

Berrocal, J.; M-Soporte tarjeta; 48157; 1910

Berthon, R. Société Cine; P-Inversión; 122433; 1931

Beyer, R.; C-Filtro; 46691; 1909

Beyerlen, C.; T-Ésterescopía Roentgen; 74583; 1920

Bierbum; Hansen; Lind; T-Cámara múltiple; 136813; 1934

Billard, P. M.; M-Película; 132431; 1933

Binder, K.; P-Estarcido; 94565; 1925

Bisson, A.-R.; C-Impresión; 3980; 1884

Bisson, L. J.; A-Metal; 27652; 1901

Blanco, D. ; T-Fotos varias; 57676; 1914

Blanco, D.; P-Retrato animado; 56284; 1913

Blanco, M.; C-Coloreado; 15798; 1894
Blanco, M.; Monreal, F.; P-Fotoescultura; 26069; 1900

Blanpain, F.; T-Aparato plegable; 39626; 1906

Blondel, J.; Chopin, A.; M-Placas; 55110; 1913

Boedicker, H. C.; T-Máquina copias; 72108; 1920

Bofill Homs, P.; M-Placas; 20554; 1897

Bogopolsky, J.; T-Aparato Fotocinematografía; 92533; 1925

Boixadera, J.; T-Cámara panorámíca; 31595; 1903

Bolívar, E.; T-Iluminación; 31245; 1903

Boned y Pujol; P-Fotocromo; 10514; 1890

Bonnamour, M.; M-Álbum; 24795; 1889

Bonnet, A.L.; A-Porcelana; 92323; 1925

Borzykowski, B.; M-Papel; 40316; 1907

Bottaro, E.; M-Tarjeta postal; 52707; 1912

Boucard, P.; Lemaire, L.; T-Ampliadora; 67429; 1918

Boucher, P.; T-Aparato exposición; 53203; 1912

Bouillaud, G.; T-Iluminación; 22095; 1898

Bradshaw, R..G; Lyell, J. C.; C-Película; 57766; 1914

Bramwell, Jo. E.; T-Aparato; 112528; 1929

Breitbath, F.; M_Soporte tarjeta; 18664; 1896

Brevetti Ughemar; T-Telefotografía; 82270; 1922

Briales, S.; T-Proyector; 93438; 1925

Bright, F. E.; P-Reproducción; 19781; 1896

Brock, A.; A-Cartografía; 64440; 1917

Broighton, W. H.; T-Aparato; 110996; 1929

Bromograf, A.G.; P-Copias; 72319; 1920

Brooks, A. A.; Watson, G.; T-Aparato; 2854; 1901

Broquier, P.; M-Placas secas; 70427; 1919

Broto, J.; T-Montaje; 7472; 1923

Browne, E. J.; C.Multicolor; 39293; 1906

Brugada, V.; Brugada García, N.; A-Repiés; 86261; 1923

Brugada, V.; T-Trípode; 95354; 1925

Brulin, C. L. E.; T-Proyector; 133349; 1394

Bueno, R.; A-Impresión; 63994; 1917

Bulbena (v. J. Masó), R.; Masó, M.; Masó, A.; Masó, M. T.; Masó, J.; Masó, J. L.P-Emulsión; 15962; 1909

Bulbena, César; Girbal, J.; T_Fotos alteradas; 78732; 1921

C.W.Retting \& Co.; T-Aparato; 112519; 1929

Cabanach; Güell et al.; T-Cámara automática; 13540; 1892

Cabrera, L.; M-Tarjeta postal; 64613; 1917

Cabrera, L.; M-Tarjeta postal; 64956; 1917

Cabrera, L.; M-Tarjeta postal; 65971; 1917

Calvet, E. A.; T-Aparato automático; 27440; 1901

Cam Syndicate; T-Cámara enfoque; 125939; 1932

Camiller, J.; Hay, A.; T-Pantallas; 76010; 1920

Camiller, J.; M-Tarjeta postal; 67873; 1918

Campion, P.; P-Estarcido; 94565; 1925

Campos, G. y Clivillés; P-Fotodecoración; 46050; 1909

Canals, J.; T-Foto ambulante; 141191; 1934

Canson \& Montgolfier; M-Papel; 4091; 1865

Canto, J.; T-Báscula; 7741; 1887

Cantó, J.; T-Cámara; 7510; 1887

Caparrós, J.; M-Cliché; 93965; 1925

Capin, J.; Lecocq, A.; M-Álbum; 37082; 1905

Capron; Duvivier; Ponselle; M-Cliché; 5744; 1877

Carabias, C.; A-Metal; 60466; 1915

Carabias, C. ; A-Metal; 90062; 1924 
Carbonnelle, H.; T-Telefotografía; 40307; 1907

Carranza, E.; A-Retrato; 121154; 1930

Carranza, E.; T-Obturador; 93746; 1925

Casado, E. ; Lacruz, A. ; P-Foto nocturna; 31066; 1903

Casado, J.; M-Chasis; 42868; 1908

Casado, J.; M-Chasis; 53249; 1912

Casado, J.; M-Soporte carte de visite; 42178; 1907

Casado, J.; T-Esteresocopia; 57873; 1914

Casado, L.; T-Fotominiatura; 65505; 1907

Case, T. W.; P-Anotaciones; 91334; 1924

Cassan, J.; M-Clichés; 7255; 1887

Castillejo, R.; A-Cuero; 141227; 1936

Castillo, E.; A-Foto aérea; 23674; 1899

Castillo, E.A-Foto aérea; 29713; 1902

Catini, A.; M-Cartón; 73068; 1920

Cea Bermúdez, F.; A-Metal metalina: 29205; 1902

Cellérier, L. J. H.; C-Coloreado; 6644; 1887

Cellérier, L. J. H.; P-Carbón; 5029; 1885

Cembrano, P.; T-Iluminación; 18932; 1896

Ceñal, R.; M-Placas y papel; 26940; 1900

Cepero, L.; P-Foto vistas; 59270; 1914

Cervenka, E.; C-Sistemas; 65429; 1917

Chacón, J.; P-Revelado; 110166: 1928

Chafes, R.; M-Soporte tarjeta; 9386; 1889

Chaine; Durand; Sallonier; C-Sistemas Fotonatura; 2819; 1882

Chapman, W.; Bull, H. H.J.; C-Película; 115521; 1929

Chapman, W.; C-Sistemas; 125212; 1931

Charley, J. Ch.; M-Película; 24097; 1899

Chemische Fabriek L. Grinten; P-Reproducción; 102832; 1927

Cheron, E.; Mendoza, L.; T-Aparato automático; 13819; 1892

Chesnay, É.; P-Esmalte laca; 18055; 1895

Chestanoff, P; Merejkovsky, B.; P-Revelado; 93410; 1925

Chevallier, F. A.; T-Aparato panorámica; 3050; 1865

Claret, R.; T-Secadora abrillantadora; 128708; 1932

Clark, A. J.; C-Tricromía; 109844; 1928

Clemot, T.; Clemot, A.; A-Impresión; 25591; 1900

Clifton, E.; Wells, A. ; C-Sistemas; 46579; 1909

Coca, T.; Leaburu, M.; T-Áparato; 9969; 1926

Coca, T.; Leaburu, M.; T-Cámara; 89868; 1924

Coca, T.; Leaburu, M.; T-Prensa rotativa; 92187; 1925

Coca, T.; Leaburu, M.; T-Secadora; 91149; 1924

Coca, T.; Leaburu, M.; T-Secadora; 91818; 1924

Coca, T.; T-Ampliadora; 82258; 1922

Cohn, Irwin E.; Tait, Wifred E.; T-Proyector; 14957; 1936

Colominas, T.; M-Placas secas; 12642; 1891

Colorco; T-Cámara; 75194; 1920

Conquerant, Ch.; T-Cámara espia; 16843; 1895

Cooper, E. E.; Trodel, A. T.; M-Cliché; 134211; 1934

Corning Glass Works; T-Proyector; 71346; 1919

Corpas, E.; T-Iluminación; 27575; 1901

Corpas, E.; T-Iluminación; 27623; 1901

Cortés, Á.; A-Tela; 116838; 1930

Costa, O.; P-Reproducción; 23346; 1898

Costales, F.; P-Transparencia; 50692; 1911

Cotillon, A.; T-Aparato impresión; 39941; 1907
Coventry, H.; T-Aparato lavado; 2605; 1900

Crehuet, C.; P-Revelado-Fijado; 85665; 1923

Crespo, M.; A-Mármol; 146707; 1939

Crozat, L. \& Crozat, N.; P-Fondos; 2546; 1862

Csiszar, F. H.; M-Papel; 17469; 1895

Cubillo, L.; T-Cámara; 54703; 1913

Cubillo, L.; T-Cámara; 72532; 1920

Cubillo, L.; T-Portaplacas; 72532; 1920

Cuenin \& Co.; C-Aparato tricromía; 89375; 1924

Cumming, J. G.; M-Soporte tarjeta; 10416; 1890

Cuyás; M-Cliché; 66632; 1918

Cuyás; T-Prensa; 61239; 1915

Cuyás; T-Prensa; 61668; 1916

Dalmau, J.; P-Realidad; 69023; 1919

Dassonville, L.; C-Positivos; 123499; 1931

Dassonville, L.; C-Positivos; 124611; 1931

Daylight Film Corporation; A-Reproducción; 77930; 1921

Decke, W.:T-Portaplacas; 56030; 1913

Deckel, F.; T-Obturador; 101765; 1927

Del Amo y Gutiérrez; M-Álbum; 107548; 1928

Del Amo y Gutiérrez; M-Álbum; 111441; 1929

Derepas Freres; M-Papel; 28442; 1901

Dessler \& Walter; P-Emulsión; 134437; 1934

Dickerson, E. N.; T-Cámara automática; 18729; 1896

Dickinson; Hepburn; T-Estereoscopia; 72775; 1920

Dickinson; Hepburn; T-Estereoscopia; 82987; 1922

Didier, L. J.-B.; C-Sistemas: 100164; 1926

Dorel, F.; T-Planchas; 68444; 1918

Driggs, L. L.; Faber, H. B.; T-Iluminación; 117105; 1930

Dropioswki, Th.; M-Películas; 48967; 1910

Ducos, L. A.; Bercegol, R.; C-Policromía; 39799; 1907

Ducos, L.; C-Sistemas; 5513; 1876

Dufay, L Coleurs Co.; C-Sistemas; 99038; 1926

Dufay, L. Coleurs Co.; C-Pruebas; 83551; 1922

Dufay, L.; C-Sistemas; 89200; 1924

Dufay, Plaques; C-Pantalla; 43352; 1908

Dupuis, E.T-Proyector; 50102; 1911

Durá, J.; A-Fotograbado; 49782; 1911

Durá, J.; A-Fotograbado; 55631; 1913

Durán y Mújica; M-Placas secas; 27656; 1901

Durán, A.; T-Aparato automático; 10758; 1890

Durán, A.; T-Aparato automático; 12649; 1891

Durán, A.; T-Aparato automático; 16558; 1894

Durán, J. ; P- Relieve; 52612; 1912

Durán; Hernando; Díez; T-Aparato automático; 23011; 1898

Dye impression Photo Ltd; P-Negativos teñidos; 75626; 1920

E. \& H. T. Anthony \& Co..; M-Papel; 5583; 1886

Ehlermann, E.; P-Foto retícula; 29129; 1902

Electrical Research; T-Áparato reproducción; 109451; 1928

Ellero, U.; T-Telefotografía; 54206; 1912

Ellrich J.; T-Disparador; 132930; 1933

Enjalbert, T. E.; T-Aparato automático; 13519; 1892

Enjalbert, T. E.; T-Aparato automático; 9986; 1889

Escandón, R.; Marasí, S.; P-Grabado; 9680; 1889

Escrivá, F B.; A-Impresión; 127751; 1932

Espino, R.; P-Pruebas; 109738; 1928 
Espino, R.; T-Óptica; 109739; 1928

Espino, R.; P-Reproducción; 110533; 1928

Fabro, T.; M-Papel; 53168; 1912

Farbenindustrie; C-Revelado; 142001; 1936

Farbenindustrie; C-Copias; 145006; 1938

Farbenindustrie; C-Emulsión; 145057; 1938

Farbenindustrie; C-Material; 143500; 1936

Farbenindustrie; C-Material; 143903; 1937

Farbenindustrie; C-Material; 143934; 1937

Farbenindustrie; C-Material; 144867; 1938

Farbenindustrie; C-Material; 145052; 1938

Farbenindustrie; C-Material; 145751; 1938

Farbenindustrie; C-Reproducciones; 143569; 1937

Farbenindustrie; C-Revelado; 142661; 1936

Farbenindustrie; C-Revelado; 145056; 1938

Farbenindustrie; C-Sistemas; 142991; 1936

Farbenindustrie; C-Sistemas; 143200; 1936

Farbenindustrie; C-Sistemas; 143200; 1936

Farbenindustrie; C-Sistemas; 143846; 1937

Farbenindustrie; C-Sistemas; 145053; 1938

Farbenindustrie; C-Sistemas; 145170; 1939

Farbenindustrie; C-Sistemas; 146022; 1938

Farbenindustrie; C-Sistemas; 146607; 1939

Farbenindustrie; C-Sistemas; 14845; 1936

Farbenindustrie; C-Sistemas; 14858; 1938

Farbenindustrie; C-Sustracción; 145049; 1938

Farbenindustrie; C-Transparencia; 143501; 1937

Farbenindustrie; M-Película; 113681; 1929

Farbenindustrie; M-Película; 114192; 1929

Farbenindustrie; M-Película; 129518; 1933

Farbenindustrie; M-Película; 132036; 1933

Farbenindustrie; P-Emulsión; 134797; 1934

Farbenindustrie; P-Emulsión; 111979; 1919

Farbenindustrie; P-Emulsión; 142276; 1936

Farbenindustrie; P-Emulsión; 142776; 1936

Farbenindustrie; P-Emulsión; 143924; 1935

Farbenindustrie; P-Emulsión; 14436; 1937

Farbenindustrie; P-Fotos sin plata; 14499

Farbenindustrie; P-Revelado; 139752; 1935

Farbenindustrie; P-Revelado; 142790; 1936

Farbenindustrie; P-Emulsión; 134796; 1934

Farbenindustrie; P-Foto rápida; 132502; 1933

Fargier, A.; Charavet, N.; P-Tintas; 2280; 1861

Farguell, J.; M-Placas secas; 66249; 1918

Fau, J.; M-Tarjeta postal; 56591; 1913

Faucompré, É. de; M-Chasis; 12992; 1892

Faucompré, É.; M-Chasis; 13579; 1892

Faulstich, P.; C-Negativos; 75580; 1920

Favre, L.; C-Sistemas; 928; 1880

Fernández, A. (Napoleón); A-Foto espejo; 3852; 1884

Fernández, A. (Napoleón); A-Porcelana; 2695; 1882

Fernández, E.; M-Soporte tarjeta; 69502; 1919

Fernández, D.; P-Reproducción impresa; 125829; 1932

Fernández, G.; Martín, V.; M-Soporte aluminio; 119339; 1930

Fernández y Carbonell; M-Papel; 60063; 1915

Ferradas, M.; P-Revelado-Fijado; 84222; 1923
Ferrer, A. ; P-Foto mágicas; 16155; 1894

Ferriter, J. P.; Peters, Th. J.; M-Cliché; 61962; 1916

Fiol, F.; A-Tríptico; 62811; 1916

Foiret, A. A.; T-Aparato Pratic; 16405; 1894

Foiret, A. A; T-Aparato Pratric; 15009; 1893

Fontaine, H.; T-Estereoscopia; 4752; 1870

Forest, L.; A-Vistas; 95583; 1925

Forunes, E.; Diamant, H.; P-Revelado-fijado; 140715; 1935

Fougerat, Ch.; T-Proyector; 34959; 1904

Fox, W. J.; T-Cámara foto animada; 10838; 1929

Fox, W. J.; T-Cámara foto animada; 114597; 1929

Fox, W. J.; T-Cámara foto animada; 115451; 1929

Frankie, P.; Heidecke, R.; T-Cámara estuche; 133590; 1934

Franzen, Ch.; A-Cristal; 84029; 1923

Freeman, A.; T-Óptica; 69783; 1919

Freeman, A.; T-Óptica; 69783; 1919

Frerich, P. M.; M-Tarjeta postal; 48675; 1910

Fullenlove, M. C.; T-Aparato reproducción; 98915; 1926

Fussli, O. et Co.; M-Álbum; 9518; 1889

Gaertner, F.; P-Fotoescultura; 35995; 1905

Gamoneda, E.; P-Impresión; 50024; 1911

Garchey, L. A.; C-Película; 28091; 1901

García, E.; M-Tarjeta postal victor; 42929; 1908

Garriga, C.; T-Cámara oftalmología; 138598; 1934

Garriga, R.; M-Papel; 103438; 1927

Garriga, R.; M-Papel; 116570; 1930

Garriga, R.; T-Proyector; 33272; 1904

Gaspar, B.; C-Sistemas; 127340; 1932

Gaspar, B.; C-Sistemas; 137734; 1935

Gateau, E. P-Carbón; 150; 1878

Gateau, E.; Monckhoven, D.; P-Carbón; 46; 1878

Gateau, J. Th.; P-Emulsión; 41609; 1907

Gatell, V.; Cercada, A.; M-Placas secas; 30573; 1902

Gay, E.; P-Imágenes; 99723; 1926

Gay, E.; P-Imágenes; 99730; 1926

Gebruder Schwarz; M-Placas: 82113; 1922

General Aniline \& Film Co.; C-Sistemas; 172755; 1916

Gevaert Photo; P-Copias; 131943; 1933

Gevaert, L. et Co.; M-Carretes; 73945; 1920

Gevaert; M-Película; 82746; 1922

Gevaert; P-Revelado; 138038; 1935

Giner, R.; A-Abanicos; 65256; 1917

Gleichmar, A.; C-Negativos; 72524; 1920

Glover, E. S.; M-Álbum; 637; 1879

Goldschmidt, H.; P-Foto rápida; 23057; 1898

Gómez, F.; P-Revelado; 86494; 1923

Gómez, F.; T-Iluminación; 67469; 1918

Gómez, J.; P-Fijado; 89800; 1924

Gómez, J.; P-Fijado; 92388; 1925

Gómez García, F.; C-Cronofotográfico; 49256; 1910

Gómez García, F.; P-Relevado; 53723; 1912

Gómez García, F.; P-Revelado; 50079; 1911

Gómez García, F.; P-Revelado; 53574; 1912

Gómez García, F.; P-Revelado; 53721; 1912

Gómez García, F.; P-Revelado; 54699; 1913

Gómez García, F.; P-Revelado; 55780; 1913 
González, Á.; T-Estereoscopia; 92249; 1925

González. B.; T-Ampliadora; 27558; 1901

González, F.; P-Foto inalterable; 4817; 1871

González; Suárez; Pacheco; T-Dispositivo; 96443; 1925

Gorsky, S. M. P.; C-Tricromía; 79457; 1921

Gorsky, S. M. P.; T-Óptica; 81611; 1922

Gorsky, S.; Michael, P.; C-Sistemas; 108354; 1928

Grandin, E. J. B.; A-Esmalte; 16852; 1895

Grenier Art Co.; C-Retratos; 26361; 1900

Grieshaber Frères et Co.; P-Emulsión; 112160; 1929

Grossi, S.; M-Chasis; 54039; 1912

Grossi, S.; T-Aparato impresor; 63279; 1916

Guanderax, E.; T-Cámara; 119486; 1930

Guanderax, E.; T-Cámara; 1284; 1931

Guerrero, L.; T-Cámara estereoscópica; 76723; 1921

Guillén, B. A.; T-Aparato automático; 139369; 1935

Guillén, B. A.; T-Iluminación; 102579; 1927

Guillén, G. J.; T-Telegrafía; 40298; 1907

Gumpel, K.; Kaftanski, F.; T-Cámara; 137249; 1935

Gurich, J.; Ochotorena, Á.; A-Reproducción; 57100; 1913

Gurtner, A. A.; C-Impresión; 31784; 1903

Gutiérrez, R.; M-Tarjeta postal Argos; 44937; 1909

Gutiérrez Quintana, E.; A-Retrato; 16863; 1895

Guy, A.; A-Grabado; 4301; 1867

Hagen; Mathyns; Daamen; P-Albúmina; 66732; 1918

Harbers, T.; P-Copias; 55819; 1913

Hart, S.; Stealey, J.; T-Aparato automático; 110427; 1928

Hart, S.; Stealey, J.; T-Obturador; 110428; 1928

Haworth-Booth, M.; T-Cámara; 124295; 1931

Haworth-Booth, M.; T-Cámara; 124305; 1931

Heck, L. J.; P-Relieve; 58634; 1914

Heinen, Th.; T-Aparato revelado; 60844; 1915

Helmert, B.; M-Placas; 20286; 1897

Hennicke, A.; T-Cámara estereoscópica; 145662; 1939

Henri, A.; Lassus, J.; P- Relieve; 137815; 1935

Heras, Á.; P- Revelado-fijado; 95325; 1925

Heras, Á.; P-Revelado-fijado; 95742; 1925

Hermite, J. C. A.; T-Bastidor; 6604; 1887

Hernández, J.; T-Laboratorio; 64415; 1917

Hernández Barasoain, J.; P-Pruebas; 36604; 1905

Hernández Tejada, J.; C-Coloreado; 1548; 1857

Herrera, S.; T-Recortadora; 58241; 1914

Herrero Puerta; M-Estuches; 20792; 1897

Hesekiel, A.; P-Revelado; 30758; 1902

Hess-Ives Co.: C-Sistemas; 56164; 1913

Hess-Ives Co. ; A-Cartografía; 65765; 1917

Hess-Ives Co.; C-Sistemas; 56724; 1913

Hess-Ives Co.; C-Sistemas; 60556; 1912

Hidalgo, M.; A-Metal; 59730: 1915

Horák, J.; T-Retoque; 54589; 1913

Hörner, E.; A-Foto aérea; 138078; 1935

Horst, L.; C-Máquina; 13113; 1933

Hosch, J.C.; C-Sistemas; 8857; 1888

Houston, D.; T-Cámara: 18691; 1896

Huber, A.; Simons, W. ; T-Aparato fotoinvisible; 84557; 1923

Huber, A; Simons, W. ; T-Cámara; 84557; 1923
Hudeley, V.; T-Estereoscopia; 131229; 1933

Huebner Bleistein Co.; M-Cliché; 51592; 1911

Huertas, M.; T-Prensa; 68265; 1918

Huet et Co.; T-Cámara Foto animada; 45870; 1909

Huet, H. L.; T-Aparato; 170275; 1900

Hulster, J. A.; T-Aparato automático; 30353; 1902

Hurtado de Mendoza, M.; A-Fotograbado; 28500; 1901

Iglesia, J.; T-Iluminación; 105355; 1957

Isaac, G.; P-Impresión; 16898; 1895

Ives, F.; T-Estereoscopia; 34679; 1904

Ivorra y Payá; T-Cromo-relieve; 38807; 1906

Jelley, E. E.; P-Emulsión; 90533; 1924

Jellinek, K.; T-Secadora; 59856; 1915

Jewwey, E.; T-Producción; 97782; 1926

Jiménez Villalobos, J.; A-Foto recorte: 82260; 1922

Jimeno, R.; A-Foto aérea; 73454; 1920

Jimeno, R.; A-Fotoaérea; 68778; 1918

Joarizti y Mariezcurrena; A-Fotograbado; 4505; 1884

Joh, Friedr. Wallmann \& Co.; A-Impresión; 21189; 1897

José Melguizo y Co.; A-Anuncio foto; 66394; 1918

Josepho, A.M.; T-Aparato automático; 95294; 1924

Josepho, A.M.; T-Cámara; 107911; 1928

Jos-Pe Farbenphoto G.; C-Impresión; 95607; 1925

Jos-Pe Farbenphoto G.; C-Óptica; 92239; 1925

Joux, L.; T-Aparato de Escamoteo; 16456; 1894

Kahlert, A.; P-Trama; 143004; 1936

Kalle \& Co. A.G.; M-Papel; 84344; 1923

Kalle \& Co.; P-Diazofoto; 111275; 1929

Kalle \& Co.; P-Reproducción; 104515; 1927

Kalle \& Co.; P-Reproducción; 104967; 1927

Karaflat, J.; Cerny J.; P-Celulosa; 130359; 1933

Kaufer, R.; A-Identificación; 137057; 1935

Keller-Dorian Societe Cine-Photo; C-Sistemas; 109869; 1928

Keller-Dorian Societe; T-Objetivo; 96448; 1926

Keller-Dorian, A.; C-Pantalla; 77035; 1921

Keppler, C.; T-Disparador fotoclip; 65037; 1917

Kitseé, I.; T-Pantallas; 87356; 1923

Kodak; C-Sistemas; $138641 ; 1935$

Kodak; C-Sistemas; 138642; 1935

Kodak; C-Sistemas; 139133; 1935

Kodak; M-Película; 105629; 1927

Kodak; M-Película; $123134 ; 1931$

Kodak; M-Película; 123111; 1931

Kodak; P-Emulsión; 39192; 1935

Konieczny, A.; T-Iluminación; 73843; 1920

Konieczny, A.; T-Proyector; 60714; 1915

Kopp, R.; C-Sistemas; 12729; 1891

Korn, A.; T-Telefotografía; 43055; 1908

Korn, A.; T-Telefotografía; 91999; 1924

Korsten; Melies; Reulos; T-Cámara foto animada; 19610; 1896

Kosmoskop; T-Aparato estroboscópico; 25067; 1899

Kraf \& Steudel Papiere; A-Impresión; 97142; 1926

Krakow, E.; P-Fototipogragía; 4413; 1884

Kruse, C.; T-Cámara; 5958; 1886

Kunkler, E.; Brunner, J.; A-Pintura y grabado; 4335; 1884 
Kunkler, E.; Brunner, J.; A-Impresión; 3933; 1884 Laborda, J. J.; P-Fotocromo; 10704; 1890 Labourse, G.; P-Emulsión; 128866; 1932 Lacasa, F.; P-Autocromas; 69323; 1919 Lacher, C.; C-Impresión multicolor; 77632; 1921 Lacoste, J.; M-Tarjeta postal; 53749; 1912 Lacoste, J.; T-Iluminación; 44601; 1912 Lafarge, J.; T-Aparato efecto; 2561; 1862 Lafora, J.; P-Imagen continua; 62905; 1916 Lafora, J.; P-Imagen continua; 63270; 1916 Lafora, J.; P-Imagen continua; 64172; 1917 Lafuente, G. E.; P-Esmalte; 103972; 1927 Lafuente, G. E.; P-Positivos; 103974; 1927 Lafuente, G. E; A-Esmalte; 103973; 1927 Lage, E. A.; C-Placas sensibles; 82167; 1922 Lage Farben PhotoAuslands; C-Negativos; 100368; 1926 Lamblin, A.; T-Aparato revelado; 57570; 1914 Lamblin, A.; T-Aparato revelado; 55594; 1913 Langhans, J.; M-Soporte tarjeta; 2389; 1882 Laporta, F.; A-Impresión; 2126; 1881 Laporta Hermanos; C-Fotocromo; 24284; 1899 Laurent, J.; A-Abanicos; 3026; 1864 Laurent, J.; C-Retratos; 1321; 1855 Laurent, J.; C-Retratos; 1474; 1856 Laverdet, M.; P-Reproducción; 1138; 1854 Lawrence, G.; T-Cámara foto aérea; 41781; 1907; Leitz, E.; T-Objetivo; 127410; 1932 Leitz, E.; T-Cámara; 127226; 1932 Leon, C.; M-Clichés; 5209; 1874 Leperche, Salvadori \& Co. P-Pruebas; 11662; 1930 Lesjak, M.; M-Placas; 73485; 1920 Levy-Roth G.M.B.H.; T-Aparato; 57624; 1914 Liebert, A. \& Lafon Saint Cry, J.; T-Cámara; 2833; 1864 Liñán, F.; T-Prensa; 46712; 1909 Lipa, conde de: Ver Tarszenski, L. Llimona, J.; A-Identificación; 147492; 1939 Llimona, J.; M-Película; 125899; 1932 Llopis, J.; Mir, R.; P-Positivos; 144748; 1939 Llopis, L.; P-Fotoescultura; 65068; 1917 Llorens, J. hijo; T-Esteresocopia; 126681; 1932 Lohr y Morejón; M-Soporte tarjeta; 6477; 1886 Lombardi, A.; Lewinger, Ch.; C-Coloreado; 381; 1879 López, F.; P- Relieve; 5347; 1875

López, J. F.; P- Foto microscópica; 2370; 1861 López de Pablos, E.; A-Anaglifos; 91872; 1924 Lubishez, B. E.; T-Objetivo; 119288; 1980 Lubosher, B. E.; C-Óptica; 120968; 1930 Lumière, Hermanos; C-Sistemas; 17281; 1895 Lumière, Hermanos; T-Cámara panorámica; 27942; 1901 Lumière, L. J.; P-Estereosíntesis; 77411; 1921 Lumière \& Ses Fils; C-Pantalla; 44008; 1908 Lumière \& Ses Fils; C-Pantalla; 50219; 199 Lumière \& Ses Fils; C-Sistemas; 34972; 1904 Lumière \& Ses Fils; C-Sistemas; 38291; 1906 Luque, J.; A-Anuncios; 77128; 1921 Luque, J.; A-Anuncios; 59512; 1914
Luque, J.; A-Abanicos; 60809; 1915

Luque, J.; A-Identificación; 119191; 1930

Luque, J.; P-Pruebas; 62001; 1916

Luque, M.; P-Relieve: 128771; 1332

Mackenstein, G.; M-Chasis; 13421; 1892

Madsen, D. L.; M-Cliché; 2567; 1900

Maezty, M.; A-Identificación; 101069; 1927

Magnus, M.; P-Relieve; 19004; 1896

Mahler, J.; T-Estereoscópica; 13357; 1934

Maluquer, M.; T-Aparato microfoto; 69986; 1919

Mampel, D.; T-Ampliadora; 121886; 1931

Mampel, G. ; T-Esmaltadora; 118640; 1930

Mampel, G.; T-Prensa; 123754

Manén, P.; P-Contraste; 123246; 1931

Mangano-Migone, G.; P-Retoque; 123387; 1931

Manquillo, A.; T-Coche artístico; 28917; 1901

Manufactura Papeles Foto; M-Papel; 64089; 1917

Manufacturas Bebes Ysuar; M-Chasis; 137761; 1935

Manufacturas Bebes Ysuar; T-Cámara; 137760; 1935

Marconi Wireless Teleg. Co.; T-Fototelegrafía; 102078; 1927

Marconi Wireless Teleg. Co.; T-Telefotografía; 96841; 1926

Marcos, M.; T-Ampliadora; 121415; 1931

Marechal, C. R.; P-Fotolitografía; 4203; 1866

Mari, E.; T-Cámara; 120196; 1930

Mariani, J. L. ; C-Coloreado; 147077; 1919

Mariné, J.; M-Papel; 63937; 1917

Marion, A.; T-Pantallas; 74894; 1920

Maroniez, P.; T-Aparato instantáneo; 13387; 1892

Martí, C.; A-Identificación 140087; 1935

Martí, F.; T-Aparato automático; 10501; 1890

Martí, L.; P-Ampliaciones; 118142; 1930

Martínez, A.; A-Esmalte/Porcelanas; 5132; 1873

Martínez, D.; T-Foto reformada; 59047; 1914

Martínez, J.; T-Cámara; 61022; 1915

Marwirz, H.; Saltmann, F.; T'Cámara plegable; 99971; 1926

Masana, J.; P-Retrato autoretrato; 124926; 1931

Mateo, F.; T-Iluminación; 134589; 1934

Maurel, L.; Etiennot, J.; C-Coloreado; 46040; 1909

Mauri, J.; A-Impresión; 107462; 1928

Max B. du Pont Vitacolor Co.; C-Sistemas; 111680; 1929

Mayall, J. F. E.; T-Producción impression; 7033; 1887

Meinhardt, O.; T-Prensa; 108073; 1928

Meisenbach, J.; M-Cliché; 2493; 1882

Melero, A.; A-Metal; 83188; 1922

Mena, J.; P-Retrato; 106008; 1928

Mena, J.; P-Retrato; 57653; 1914

Méndez, J.; Leivar, A.; A-Tejidos; 32607; 1903

Méndez, J.; Leivar, A.; A-Tejidos; 32791; 1903

Méndez, J.; P-Impresión; 21936; 1897

Messter; A-Foto aérea; 69917; 1919

Metalline-Platten; P-Fijado; 27675; 1901

Metalline-Platten; P-Fijado; 29715; 1902

Metalline-Platten; P-Fijado; 31037; 1903

Meursing, A. H.; Gratama, E. J.; M-Papel; 103483; 1927

Mikut, P. O.; T-Espejo; 134406; 1934

Mimosa A.G.; C-Coloreado; 71224; 1919 
Mingueza, T.; T-Estereoscopia; 140391; 1935

Miralles, B.; T-Proyector; 20752; 1897

Miralles, B.; T-Proyector; 20778; 1897

Miralles, H.; M-Cubeta; 28614; 1901

Miret, R.; M-Tarjeta postal; 105144; 1927

Moltó, R.; P-Reproducción; 55848; 1913

Monney, C. \& Mauzaise, C.; M-Papel; 4162; 1866

Montero, D.; Tirado, B.; A-Porcelana; 33391; 1904

Montero, D.; Tirado, B.; A-Porcelana; 33815; 1904

Montero, D; Tirado, B.; A-Porcelana; 32541; 1903

Montigny, A.; P-Reproducción; 90689; 1924

Montigny, A.; P-Reproducción; 90803; 1924

Montigny, A.; T-Aparato reproducción; 90647; 1924

Mora, A.; P-Emulsión; 38171; 1906

Moreno, J. N.; M-Tarjeta postal; 60981; 1915

Moreno, J. N.; M-Tarjeta postal; 63300; 1916

Moreno y Ruiz, M.; P-Calcografía; 3068; 1865

Moscoso, G.; A-Esmalte; 32639; 1903

Moscoso, G.; C-Sistemas Modern Style; 32638; 1903

Motta, D.; Rugiu, E.; Villaín, A.; P-Chasis; 71666; 1919

Müller, H.; T-Aparato prensa; 27580; 1906

Müller, H.; T-Iluminación; 38691; 1906

Müller, Hermanos; T-Aparato prensa; 38696; 1906

Muller, L.; T-Esmaltadora; 139780; 1935

Multipose Portable Camera; M-Película; 114096; 1929

Multipose Portable Camera; M-Film-pack; 112731; 1929

Multipose Portable Camera; P-Revelado; 112741; 1921

Multipose Portable camera; T-Ampliadora; 112728; 1929

Multipose Portable Camera; T-Aparato revelado: 112742; 1929

Multipose Portable Camera; T-Aparato; 114068; 1929

Muntané, J.; M-Álbum; 122080; 1931

Munuera, J.; T-Foto indirecta; 142970; 1936

Muñoz, F.; A-Metal; 52278; 1912

Muñoz, F.; P-Caricatura; 64638; 1917

Muñoz, F.; T-Prismas; 62548; 1916

Muñoz, J.; M-Placas; 16873; 1900

Murga, L.; T-Proyector; 20915; 1897

Murray, C. H.; T-Aparato automático; 108593; 1928

Murray, H. D.; Spencer, D. A.; C-Película; 138755; 1935

Nachet, C. ; C-Tricromía; 90016; 1924

Nachet, C.; T-Aparato imagen monocroma; 39423; 1906

Namias, R.; P-Relieve; 41063; 1907

Naranjo, M.; Bosóms J.; T-Estereoscopia; 100847; 1926

National Photo Co.; M-Placas secas; 15050; 1893

Navarro, A.; A-Esmalte; 91849; 1924

Navarro, A.; T-Ampliadora; 118624; 1930

Navarro, D.; A-Porcelana; 92130; 1925

Nebel, M. E.; T-Cámara; 132538; 1933

Nebot, J.; A-Tejidos; 78335; 1921

Nederlandsch Laboratorium; C-Sistemas; 136615; 1934

Neithold, C.; T-Bastidor; 142908; 1935

Neumann, H. T.; T-Cámara; 133661; 1934

Neumayer, L.; T-Aparato con refector; 23607; 1899

Nicolau, T.; Nicolau, J. M.; T-Aparato; 141636; 1936

Nicolau, T.; Nicolau, J. M.; T-Negativos; 137880; 1935
Nicolau, T.; Nicolau, J. M.; T-Negativos; 141637; 1936

Nieto, C. P-Pegado adherol; 96988; 1926

Nieto, C.; P-Fotocelina; 26011; 1900

Nieto, C.; P-Pegado adherol; 58573; 1914

Nieto, C.; P-Pegado Adherol; 60531; 1915

Nikolaus, E.; T-Obturador; 56833; 1913

Nocher, A.; P-Albúmina; 4663; 1869

Nordmann, C.; T-Proyector; 130993; 1933

Nordmann, Ch.; C-Reproducciones; 143569; 1937

Novell, L.; T-Visor; 117859; 1930

Nueda, L.; M-Chasis; 80163; 1921

Olavarrieta, A.; C-Sistema Linicolor; 63538; 1916

Olavarrieta, A.; P-Fosforescente; 47052; 1909

Oliver, F.; C-Bicromía; 121436; 1931

Oliver, F.; P-Toma de fotos; $122647 ; 1931$

Oliver, F.; M-Película; 119424; 1930

Oliver, F.; P-Positivos bicolor; 121846; 1931

Oliver, F.; P-Revelado; 123897; 1931

Oliver, F.; P-Superposición; 121872; 1931

Oliver, F.; T-Perfeccionamiento; 120185; 1930

Opticolor A.G.; P-Revelado; 131234; 1933

Ordovás, J.; T-Cartógrafo; 97025; 1926

Ordovás, J.; T-Estereoscopia; 82395; 1922

Ortega, P.; M-Anunciador; 12349; 1891

Ortiz; Castillo; Palomino; P-Fotoescultura; 141659; 1936

Oses, J. de; T-Iluminación; 3098; 1883

Pacheco, J.; P-Viraje; 63440; 1916

Pagán, E.M-Chasis Verascopo; 37902; 1906

Pagés, J.; Santes, A.; M-Papel; 30509; 1902

Pagés, J.; Santes, A.; M-Placas; 30510; 1902

Palau, A.; M-Película; 77321; 1921

Palau, A.; T-Marcador; 89840; 1924

Palau, A.; T-Pinzas graduables; 88402; 1924

Palomeque, M.; P-Reproducción; 120200; 1930

Papeles cianográficos; M-Papel; 103357; 1927

Papeles cianográficos; M-Papel; 99410; 1926

Papiers Pelliculaires Pin; M-Película; 61509; 1916

Parera, J. B.; A-Cristal; 78488; 1921

Parker, E. W.; C-Coloreado; 6841; 1887

Pascal, F.; T-Cámara; 36089; 1905

Pastor, J.; A-Foto espejo; 137447; 1935

Pathé Cinema; M-Chasis; 90956; 1924

Pech, J. L.; T-Proyector; 69834; 1919:

Pellicer Sala, J.; A-Abanicos; 81099; 1922

Peña, F.; T-Proyector diapositiva; 136597; 1934

Peña, J.; P-Positivos; 144253; 1938

Pérez García, C. ; A-Anuncios; 25520; 1900

Pérez, L.; Nieto, J.; T-Aparato automático; 113986; 1929

Pérez, L.; Nieto, J.; T-Aparato automático; 117971; 1930

Pérez, M.; P-Reproducción; 44126; 1938

Pérez-Agua, C.; M-Fondo; 5301; 1912

Philbrook, B. S.; C-Sistemas; 40645; 1907

Philippi, L. H.; P-Reproducción; 2156; 1882

Philippi, L. H.; P-Reproducción; 2759; 1882

Philips Gloeilampen; P-Rayos ultravioletas; 128164; 1932

Philips Gloeilampen; P-Rayos; 123907; 1931 
Philips Gloeilampen; T-Iluminación; 132041; 1933 Philips Gloeilanpen; P-Imagen contrastada; 121989; 1931 Photo des coleurs; C-Placas; 48044; 1910 Photo des coleurs; C-Tricromía; 46247; 1909 Photogravure Rotative; M-Cliché; 57179; 1913 Photoline; D.; A-Impresión; 121931; 1931 Photomaton Parent; T-Aparato automático; 109159; 1928 Photomaton Parent; T-Aparato automático; 118583; 1930 Photomaton Parent; T-Aparato; 117284; 1930 Pictet, L.; Cantoni, M.; T-Estereoscopia; 87600; 1923 Pietzner, C. ; P-Relieve; 22419; 1898 Pietzner, C.; P-Relieve; 22747; 1898 Pifer, G. N.; M-Placas; 30117; 1902 Pifer, G. N.; P-Emulsión; 30119; 1902 Pifer, G. N.; T-Aparato automático; 30118; 1902 Pikington, H. M.; M-Cliché; 57762; 1914 Pikington, H. M.; P-Reproducción; 57763; 1913 Pikington, H. M.; P-Reproducción; 57764; 1914 Pikington, H.M.; A-Reproducción; 54162; 1912 Plá Talens, V.; P-Fondos; 139531; 1935

Planas, L.; M-Tarjeta postal; 65186; 1917 Plauber Industrial; P- Relieve; 118351; 1930 Plon, E. Mourrit et Cie.; C-Sistemas; 18259; 1895 Portet, V.; A-Abanicos; 64573; 1917 Postergraph Incorp.; M-Cliché; 110214; 1928 Postergraph Incorp.; T-Planchas; 112167; 1929 Preiss, L.; C-Tricomía; 92685; 1925

Preiss, L.; C-Tricromía; 92684; 1925 Printex Co. Ltd; A-Impresión; 54977; 1913

Publicaciones Periódicas; P-Reproducción; 5323 bis; 1875 Punyed, A.; Mercader, Á.; P-Relieve; 148956; 1939 Queryaux, J.; M-Tarjeta postal; 27931; 1901 Ramos, I.; T-Cámara estereoscópica; 117372; 1930 Ramspeck,; Schafer; Harms; T-Aparato auto; 11369; 1890 Reeves, J.; C-Colorado; 4960; 1872 Reignier, J.; Morand, F.; T-Ampliadora; 20272; 1897 Riaza, M.; A-Retrato; 61295; 1915 Riba, S.; T-Prensa; 46653; 1909 Riera, J.; P-Revelado; 142120; 1936 Riera, J.; T-Cámara fotogramas; 144019; 1938 Rieusset Co.; M-Cliché; 97305; 1926 Rimailho, É.; T-Aparato hemeráscopo; 21650; 1897 Río, D.; M-Tarjeta postal; 38428; 1906 Riudavets, J.; P-Exposición; 60102; 1915 Riudavets, J.; T-Cámara foto animada; 61688; 1916 Riva, A.; Riva, J.; Riva, C.; A-Impresión; 125292; 1931 Riva, A.; Riva, J.; Riva, C.; A-Impresión; 126091; 1932 Rivas Huetos, J.; P-Retrato; 13736; 1892 Rivetta, G.; M-Película; 78247; 1921 Rivetta, G.; T-Almacén; 78248; 1921 Rixen, C. J.; T-Aparato; 131483; 1933 Roca Togores, J.; T-Cámara Estereoscópica; 55892, 1914 Rodríguez, E.; P-Caricaturas; 140958; 1935 Rodríguez, E.; P-Siluetas; 52516; 1912 Rodríguez, M.; T-Cámara galería; 55967; 1913 Rodríguez, R.; P-Relieve; 57478; 1914
Roffs, E.; P-Emulsión; 28365; 1901

Rohrman, L.; T-Aparato reproducción; 13145; 1892 Rohrmann, L.; Rauthe, R.; P-Reproducción; 12359; 1891 Romani, F.; T-Aparato automático; 25273; 1899

Rooy, A. L. ; T-Telefotografía; 47178; 1910

Roscas, V.; Vallés, J.; M-Cubeta; 148584; 1939

Rosenfeldt, E.; T-Aparato miniatura; 52732; 1912

Rossi, S.; T-Aparato montaje; 147043; 1939

Roswag, A.; T-Aparato grafoscopio; 2245; 1882

Ruiter, J.; P-Emulsión; 41058; 1907

Ruiz, T; .A-Foto espejo; 85045; 1923

Russo, M.; Zanardo, G. B.; P-Reproducción; 16599; 1894

Sabaté, I.; M-Soporte; 107630; 1928

Sáenz, Á.; M-Soporte tarjeta; 25814; 1900

Safety Cine "Safety Film"; M-Película; 115597; 1929

Salvador, I.; P-Tonos; 147195; 1939

Sánchez, J.; A-Tejidos; 3043; 1865

Sánchez., E.; P-Caricatura; 116680; 1930

Sandig, E.; M-Soporte tarjeta; 133672; 1934

Sassoli, M.; T-Aparato; 138630; 1935

Sassoli, M.; T-Cámara estereoscópica; 145176; 1939

Savignac, L.; P-Transparencia; 101219; 1927

Savignac, L.; T-Iluminación; 141365; 1936

Saville, D. H.; A-Telefotografía; 59760; 1914

Schachinger, F.; A-Varios; 17235; 1895

Scheimpflug, Th.; A-Foto aérea; 39270; 1906

Schimmelpfennig, F.; T-Cámara; 111483; 1929

Schlessinger, M.; T-Cámara foto animada; 127846; 1932 Schmidt, K.; T-Cámara 77726; 1921

Schnitzler, G.; T-Producción transparente; 20640; 1897 Schoenfelder, P. E.; Kehle, E.; A-Impresión; 1903; 1896 Schoenfelder, P. E.; Kehle, E.; A-Impresión; 19966; 1896 Schoepp, H.; Schoepp, F.; M-Películas; 76370; 1920

Schower, M.; T-Prensa; 14521; 1893

Schwarz, A.; P-Copias; 22539; 1898

Schweitzer, H.; T-Aparato foto serie; $140112 ; 1935$

Sebastia, P.; C-Retratos; 4419; 1867

Seckendorff, F.; P-Relieve; 41961; 1907

Selbach, A.; Ramos, L.; P-Positivos; 53134; 1912

Selgas, M.; T-Aparato revelado; 79283; 1921

Selgas, M.; T-Aparato revelado; 81046; 1922

Selgas, M.; T-Aparato; 81045; 1922

Selgas, M.; T-Aparato; 81046; 1922

Selle, G.; C-Aparato fotográfico; 31969; 1903

Selle, G.; C-Aparato; 23605; 1899

Selle, G.; C-Fondos; 31584; 1903

Selle, G.; C-Negativos; 21389; 1897

Selle, G.; C-Sistemas; 21388; 1897

Selle, G.; P-Emulsión; 31971; 1903

Selle, G.; T-Diafragma; 31970; 1903

Sellier, L.; C-Coloreado; 5358; 1875

Sequeira, J.; Alabern, A.; A-Metal; 20259; 1897

Serra, S.; M-Chasis; 104066; 1927

Serra Vall-Llovera, S.; M-Chasis; 104845; 1927

Servian, Ch.; Sage, J.; C-Sistemas Radiotint; 22667; 1898

Siemens \& Halske; P-Emulsión; 134227; 1934 
Sierra, J.; M-Soporte carte de visite; 2679; 1863 Sierra Pyaba, J.; M-Soporte carte de visite; 4084; 1895 Silvestro, G.; T-Fotos positivas; 46191; 1909 Smith, J. H.; Merckens, W.; M-Película; 40043; 1907 Smith, J. H.; Merckens, W.; P-Fabricación; 40439; 1907 Sociedad Autofoto; P-Ferrotipo; 14910; 1893 Sociedad Autofoto; T-Aparato automático; 14776; 1893 Sociedad Española de Foto; A-Identificación; 115622; 1929 Sociedad Española; A-Reproducción; 2658; 1863 Sociedad Ibérica Eléctricas; T-Telefotografía; 112372; 1929 Sociedad Ibérica Eléctricas; T-Telefotografía; 112574; 1929 Société Anonyme Produits Photo; M-Película; 28788; 1901 Société Civile Photo Cine. C-Sistemas; 108167; 1928 Société Civile Photo Cine; P-Reproducción; 102573; 1927 Société d'Optique Mécanique; T-Objetivo; 69473; 1919 Société d'Optique Mécanique; T-Portaplacas; 69472; 1919 Société Française Cine; C-Impresión; 109388; 1928 Société Française Cine; C-Sistemas; 112144; 1939 Société Française Cine; C-Filtro; 113440; 1929 Société Industrielle Ap. Chimiques; P-Viraje; 104823; 1927 Société Technique d' Optique; A-Panorámica; 10737; 1928 Société Technique d' Optique; T-Aparato tiraje; 114339; 1929 Société Technique d' Optique; T-Aparato tiraje; 115121; 1929 Société Technique d' Optique; T-Iluminación; 106181; 1928 Société Technique d' Optique; T-Óbjetivo; 106873; 1928 Soler, A.; T-Cámara estereoscópica; 85037; 1923 Solsona-Ríus; T-Cámara estereoscópica; 127532; 1932 Soolen, Ch.; T-Óptica; 82386; 1922 Sosna, G. W. A. ; Biedebach, E.; C-Material; 63033; 1916 Soulé, D. J. M.; T-Obturador; 24653; 1899 Soullier, E. J. B.W.; T-Aparato tiraje; 87657; 1923 Sperati, M.; M-Cliche; 74081; 1920 Spitzer, E.; T-Producción; 34927; 1904 Splendicolor; C-Tricromía; 107334; 1928 Standard Eléctrica; T-Telefotografía; 116384; 1930 Steinberg, E.; T-Iluminación; 92203; 1925 Steinborn, G.; P-Positivos; 105363; 1927 Steinborn, G.; P-Positivos; 108178; 1928 Stereo Indupor G.; T-Estereoscopia; 75908; 1920 Still, W.M. \& Sons; Adamson, A. G.; 123917; 1931 Stille, C.; A-Anuncios; 59512; 1914

Stille, C.; T-Telefotografía; 55397; 1913 Stock, F. J. J.; C-Sistemas; 144820; 1938 Storti, V.; P-Fotogligo; 47116; 1910 Stumman, E.; P- Relieve; 23588; 1898 Subirá, A.; M-Placas; 147269 Sugrañes, M.; T-Aparato automático; 13714; 1892 Sury, J. J.; M-Papel; 56761; 1913 Sury, J. J.; M-Papel; 89424; 1924 Sutton, H.; P- Relieve; 7616; 1887 Synoloids Limited; P-Reproducción; 39140; 1906 Szcepanik, J.; C-Sistemas; 29853; 1902 Szcepanik, J.; C-Placas sensibles; 40434; 1907 Szcepanik, J.; T-Aparato proyección: 35042; 1904 Szcepanik, Jan et Cie; T-Aparato proyección; 26261; 1900 Szcepanik, Jan et Cie; A-Tejidos; 30030; 1902
Taber, F. A.; P-Relieve; 18905; 1896

Tarszenski, L.; M-Soporte carte de visite; 4300; 1867 Tartara, G.; T-Aparato automático; 69750; 1919 Tartara, G.; T-Aparato automático; 72270; 1920 Tartara, G.; T-Aparato revelado; 73666; 1920 Technicolor Motion Picture Co; T-Aparato; 118609; 1930 Teixidó, J.; M-Cliché; 14870; 1893 Telefunken Gesellschaft; T-Telefotografía; 111685; 1929 Telepantograph Gesellschaft; P-Revelado; 56312; 1913 Temino Sagredo, E.; A-Cristal opal; 73641; 1920 Thiéry, F.; M-Estuches; 27640; 1901 Thommen \& Fleury; T-Pantallas fotográficas; 74894; 1920 Thompson, F. B.; M-Película; 70385; 1919 Tideman; Glidemeister; T-Estereoscópica; 111025; 1929 Tirado, B.; A-Fotograbado; 34954; 1904 Tó Amat, J.; P-Pruebas; 124656; 1931 Tó, J.; P-Estereoscopia; 128431; 1932 Toldr Viazo, A.; T-Tarjeta postal; 40016; 1907 Torre, G.; M-Tarjeta postal; 31757; 1903 Torre, M.; M-Soporte tarjeta; 9030; 1888 Torres, L.; T-Cámara; 6334; 1886 Torres, L.; T-Cámara; 6909; 1886 Tort, J.; M-Film-pack. Roll films; 146586; 1939 Toscas, V.; Vallés, J. T-Aparato automático; 143917; 1937 Toscas, V.; Vallés, J.; T-Aparato automático; 142360; 1936 Toscas, V.; Vallés, J.; T-Aparato automático; 142554; 1936 Toscas, V.; Vallés, J.; T-Estereoscópica; 143857; 1937 Toscas, V.; Vallés, J.; T-Foto ambulante; 141191; 1934 Toupillier, A. J.; T-Estereoscopia; 46692; 1909 Toupillier, A. J.; T-Estereoscopia; 78906; 1921 Traube, A.; C-Sistemas; 75186; 1920 Trilla, J.; M-Carretes; 143799; 1937 Tru Colour Film; C-Sistemas; 126882; 1992 Truán, A.; C-Sistemas oleofotografía; 5808; 1878 Turner, A. R.; T-Aparato revelado; 73650; 1920 Tyach, J.; M-Placas; 13180; 1892 Ulysse, P.; C-Impresión luminosa; 61584; 1916 Ungerer, M. F.; C-Placas Lumiere; 56188; 1913 Union Ph. Lumière \& Jougla; C-Policromía; 110199 Union Ph. Lumière \& Jougla; P-Nitratos revelado; 89148; 1924 Universal Camera Co.; T-Cámara; 136990; 1935 Universal Camera Co.; T-Cámara; 136990; 1935 Urabayen, L.; P-Proyector diapositiva; 129668; 1933 Ureg Universal-Reklame; P-Transparencia; 103551; 1927 Urlézaga, N.; P-Estereoscópia; 103583; 1927 Val del Omar, J.; T-Proyector diapositiva: 125155; 1931 Valdés, F.; M-Soporte tarjeta; 33815; 1904 Valeiras, R.; T-Cuberta revelado; 131999; 1933 Valentí, M.; P-Reflexión; 145244; 1938 Valls, R.; C-Retratos; 2069; 1863 Varney, L. E.; C-Sistemas; 82177; 1922 Vathis, S.; C-Pirocromografía; 30028; 1902 Vaucamps, V.; C-Sistemas; 19665; 1896 Velophot Erzeugung und Vertrieb Photographischer Neuheiten; T-Cámara; 78682; 1921

Verdaguer, F.; T-Obturador; 12455; 1891 
Vergés, G.; T-Cámara; 82838; 1922

Verini, K.; T-Obturador; 46818; 1919

Vérola, P.; C-Sistemas; $112339 ; 1929$

Vicent, L.; A-Tejidos; 112939; 1929

Victorero, A. y hermanos; T-Oscilador; 101616; 1927

Vidal, A.; C-Coloreado; 51023; 1911

Vierbuche, R.; T-Secadora; 142573; 1936

Vierkotter, P.; T-Iluminación; 100807; 1926

Viganó, R.; M-Película; 127452; 1932

Vilaseca, E.; P-Movimiento; 60495; 1915

Viñas, J.; Viñas, A.; M-Cliché; 128897; 1932

Vizcayno, M.; P- Relieve; 1888; 1896

Vobach, W.; M-Papel; 95910; 1925

Voig \& Haffner; T-Iluminación; 58728; 1914

Wade, H.; C-Pantalla; 113882; 1929

Wade, H.; C-Sistemas; $113880 ; 1929$

Wade, H.; C-Sistemas; 114251; 1929

Wade, H.; C-Sistemas; 114252; 1929
Waldmann, F.; M-Chasis; 71358; 1919

Walker, J.; M-Álbum; 85125; 1923

Weber, C.; T-Obturador; 54343; 1912

Weil, V.; C-Transparencias; 95379; 1925

Weyde, H.; T-Aparato; 374; 1879

Wiese, E.; T-Cámara; 141063; 1935

Willeine, F.; P-Fotoescultura; 2659; 1863

Willis, W.; P-Litografía fotoquímica; 7707; 1887

Wolff, H. A.; T-Aparato automático; 46312; 1909

Wolff, H. A.; T-Aparato; 51867; 1911

Wolff-Heide, E.; M-Placas; 79096; 1921

Wothly, J.; P-Wothlytipia; 3046; 1865

Yus, A.; P-Foto con imágenes; 125408; 1932

Zeiss, C.; T-Estereoscopía; 77185; 1921

Zeiss, C.; T-Aparato tridimensional; 82621; 1922

Zeiss, C.; T-Cámara foto aérea; 94695; 1925

Zerkowitz, A.; M-Papel; 108347

Ziegle, N.; M-Papel; 44533; 1908 